OPEN ACCESS

Edited by:

Claire Loiseau,

Research Centre in Biodiversity

and Genetic Resources, Portugal

Reviewed by:

Guangshun Jiang,

Northeast Forestry University, Harbin,

China

Jorge Cassinello,

Estacion Experimental de Zonas

Aridas (EEZA), Spain

${ }^{*}$ Correspondence:

Therese Donovan

tdonovan@uvm.edu

Specialty section:

This article was submitted to Behavioral and Evolutionary Ecology,

a section of the journal

Frontiers in Ecology and Evolution

Received: 15 December 2020 Accepted: 17 March 2021

Published: 17 May 2021

Citation:

Blouin J, DeBow J, Rosenblatt E,

Hines J, Alexander C, Gieder K, Fortin N, Murdoch J and Donovan T

(2021) Moose Habitat Selection and Fitness Consequences During Two Critical Winter Tick Life Stages

in Vermont, United States.

Front. Ecol. Evol. 9:642276.

doi: 10.3389/fevo.2021.642276

\section{Moose Habitat Selection and Fitness Consequences During Two Critical Winter Tick Life Stages in Vermont, United States $^{\dagger}$}

\author{
Joshua Blouin ${ }^{1}$, Jacob DeBow ${ }^{1}$, Elias Rosenblatt ${ }^{1}$, James Hines², Cedric Alexander ${ }^{3}$, \\ Katherina Gieder ${ }^{4}$, Nicholas Fortin ${ }^{4}$, James Murdoch ${ }^{5}$ and Therese Donovan ${ }^{6 *}$ \\ ${ }^{1}$ Vermont Cooperative Fish and Wildlife Research Unit, Rubenstein School of Environment and Natural Resources, University \\ of Vermont, Burlington, VT, United States, ${ }^{2}$ Patuxent Wildlife Research Center, USGS Patuxent Wildlife Research Center, \\ Laurel, MD, United States, ${ }^{3}$ Vermont Fish and Wildlife Department, St. Johnsbury, VT, United States, ${ }^{4}$ Vermont Fish \\ and Wildlife Department, Rutland, VT, United States, ${ }^{5}$ Wildlife and Fisheries Biology Program, Rubenstein School \\ of Environment and Natural Resources, University of Vermont, Burlington, VT, United States, ${ }^{6}$ U.S. Geological Survey, \\ Vermont Cooperative Fish and Wildlife Research Unit, Rubenstein School of Environmental and Natural Resources, \\ University of Vermont, Burlington, VT, United States
}

The moose (Alces alces) is a charismatic species in decline across much of their southern distribution in North America. In the northeastern United States, much of the reduction has been attributed to winter tick (Dermacentor albipictus) infestations. Winter ticks are fairly immobile throughout all life stages, and therefore their distribution patterns at any given time are shaped largely by the occurrence of moose across the landscape during the peak of two critical time periods: fall questing (when ticks latch onto moose) and spring drop-off (when engorged female ticks detach from moose). We used recent land cover and lidar data within a dynamic occupancy modeling framework to estimate first-order habitat selection (use vs. non-use) of female moose $(n=74)$ during the tick questing and drop-off periods. Patch extinction and colonization rates between the fall questing and spring drop-off periods were strongly influenced by habitat and elevation, but these effects were diminished during the fall questing period when moose were more active across the landscape. From the fall questing period to the spring drop-off period, patches where colonization was high and extinction was low had higher proportions of young (shrub/forage) mixed forest at higher elevations. Further, we evaluated the fitness consequences of habitat selection by adult females during the fall questing period, when females and their calves acquire ticks. We compared Resource Selection Functions (RSF) for five females that successfully reared a calf to age 1 with five females whose calves perished due to ticks. Adult female moose whose offspring perished selected habitats in the fall that spatially coincided with areas of high occupancy probability during the spring tick drop-off period. In contrast, adult female moose whose offspring survived selected areas where the probability of occupancy during the spring drop-off was low; at present, natural selection may favor female adults who do not select the same habitats 
in fall as in spring. Our model coefficients and mapped results define "hotspots" that are likely encouraging the deleterious effects of the tick-moose cycle. These findings fill knowledge gaps about moose habitat selection that may improve the effectiveness of management aimed at reversing declining population trends.

\section{Keywords: Alces alces, habitat selection, resource selection function (RSF), fitness, lidar}

\section{INTRODUCTION}

The moose (Alces alces) is a charismatic species that has been in recent decline across much of their southern range in North America (Jones et al., 2019; DeBow et al., in press). In the northeastern United States (US), the reduction has been caused primarily by winter tick (Dermacentor albipictus) infestations (Samuel, 2004; Musante et al., 2007; Jones et al., 2019). Unlike other ungulates such as the white-tailed deer (Odocoileus virginianus), moose have not evolved behavioral strategies (e.g., programmed grooming) to counteract tick parasitism (but see Addison et al., 2019). Consequently, the number of ticks on an individual moose can be staggering, with reports as high as 90,000 ticks (Jones et al., 2019), which can lead to epizootics ( $>50 \%$ calf mortality). Research suggests that heavy tick infestations are a driving force for high mortality and low birth rates, and heavily infested calves just under 1 year old often perish in mid-April due to complications of anemia (Samuel, 2004; Jones et al., 2019; DeBow, 2020; DeBow et al., in press; Rosenblatt et al., in press).

Winter ticks are a native, one-host parasite found on a variety of mammals in the northeastern US, but commonly carry out their life cycle on moose (Samuel, 2004). Winter ticks climb and cluster on early successional vegetation to seek a host from mid-September to the first permanent snowfall, a period known as "questing" (McPherson et al., 2000; Samuel, 2004). The questing period coincides with the moose breeding period (i.e., the mid-September rut) when moose tend to be most active on the landscape. Once on a moose, winter ticks go through two life stages, nymph and adult, taking blood meals and molting between each stage (Samuel, 2004). The blood meals in latefall and early winter are not as significant as the adult blood meal in spring, when an adult female tick will typically consume 1.70-2.55 g of blood (Addison et al., 1998). After engorgement, female ticks drop from the moose into the leaf litter, where they lay their eggs and the cycle continues.

Winter ticks tend to be fairly immobile throughout all life stages, and therefore their distribution patterns at any given time are shaped largely by the patterns of occurrence of moose across the landscape (McPherson et al., 2000). As a highly mobile species, moose have the capacity to traverse great distances (e.g., a radio-collared individual in the study moved approximately $150 \mathrm{~km}$ within a few weeks). When studying moose occurrence, the distinction between habitat selection and habitat use is important. Habitat selection is the process an animal takes to actually choose or select a particular habitat given a range of options, while habitat use is the result of that choice, regardless of the available options (Johnson, 1980; Beyer et al., 2010). The selection of resources is thought to occur in a hierarchical manner, from a more coarse-scale examination of where a species selects their geographic range (first-order selection), to the home range of an individual within their geographical range (secondorder), and finally to more fine-scale examination of the habitat components within home ranges (third-order) (Johnson, 1980). Meyer and Thuiller (2006) indicate that first-order selection could be divided further into population and metapopulation levels to account for selection of areas used by populations within the geographic range.

Resource selection functions (RSFs) are a primary tool for understanding habitat selection (Manly et al., 2002; Boyce, 2006). By comparing random locations at a given scale with those actually used by the species, RSFs yield the probability of use of a resource unit (or a result that is proportional to it). Importantly, the scale at which habitat selection is evaluated shapes inferences regarding key habitat components (Boyce, 2006). For example, a study in central Ontario, Canada indicated that at a regional scale (first-order selection), moose selected areas of canopy disturbance (Forbes and Theberge, 1993), while a study in Sweden examined habitat selection at the home range scale (second-order) and found that moose selected clear-cuts and young and medium-aged forests (Cederlund and Okarma, 1988). Finally, within home ranges (third-order), moose in central Finland preferred non-pine dominated habitats and mature forests, and avoided human settlements (Nikula et al., 2004).

Understanding which habitats adult female moose select during the tick fall questing and spring drop-off periods may be important for the successful management of moose, especially during epizootic years. Adult female moose have high value for moose management as they drive recruitment of the population and significantly contribute to habitat use, home ranges, and movements of calves (Cederlund and Okarma, 1988). Previous studies have examined habitat use or selection of female moose across different seasons (e.g., Cederlund et al., 1987; Ball et al., 2001; Terry, 2015; Blouin et al., in press). However, few have examined habitat selection during the two relatively short, critical winter tick life periods. One important study in New Hampshire and Maine, United States, examined third order habitat selection during both the questing and drop-off tick periods and found that moose selected 4-16-year-old forest openings relative to their availability within their home ranges regardless of season (Healy et al., 2018). This suggests that moose key into the same habitats during both questing and drop-off periods, thus these habitats promote the winter-tick life cycle and their association with moose (Samuel, 2004; Healy et al., 2018). Forest openings provide important forage for moose, potentially attracting higher densities of moose and exacerbating the impact of winter ticks on the moose population as a whole. Although Healy et al. (2018) succinctly identified third order habitat selection within individual home ranges during these critical times, it is 
important to note that third order selection is conditional on both first and second order habitat selection (across individuals), neither of which have been examined in the northeastern US to date. Analysis of habitat selection at these scales may provide important insights into habitats that are unused or avoided during the questing and drop-off winter tick periods, and provide important context for Healy et al. (2018)'s findings.

Moreover, an understanding of how an individual's habitat selection decisions ultimately affect their fitness is lacking. Fitness can be defined as a measure of an individual's ability, relative to others, to produce viable offspring (Stearns, 1992). During epizootic years, the habitat selected by an adult female moose during the fall tick questing period may positively or negatively affect fitness and the fate of offspring (Pekins, 2020). The probability that a calf will survive to their first birthday (May) may depend on areas traversed during their first fall questing period (September). Ideally, adult female moose will select optimal habitats (i.e., those with abundant forage) during the fall questing period while limiting exposure to damaging tick loads.

Understanding moose habitat selection during the critical fall tick questing and spring tick drop-off periods and the resulting fitness consequences is a priority need for wildlife managers in the northeastern US. In recent years, moose have been declining across their southern extent, including Vermont and much of the New England region (Jones et al., 2019; DeBow et al., in press). At this time, direct management through regulated hunter harvest provides one potential means of breaking the tick-moose cycle and allowing recovery (VFWD, 2020), while indirect management through the creation or alternation of habitats may provide additional tools for breaking the cycle. As such, examination of habitat selection during the winter tick questing and drop-off period and how that selection relates to fitness may provide insights for the management of an iconic species in decline.

Our objectives were to: (1) Investigate first order habitat selection of adult female moose during each period using a multi-season occupancy framework (MacKenzie et al., 2003); and (2) Evaluate the fitness consequences of selection by comparing second-order fall questing resource selection for adult female moose that successfully reared a calf to age 1 versus those that did not.

\section{MATERIALS AND METHODS}

\section{Study Area}

The study area was in northeast Vermont, United States (Figure 1, mean latitude $=44.77^{\circ}$; mean longitude $=-71.74^{\circ}$; $1,738 \mathrm{~km}^{2}$ ). This area contains the highest density of moose in the state and represents an important region that connects populations in New Hampshire and Maine with those in New York and southern Quebec (Pearman-Gillman et al., 2020). The study area encompassed two state Wildlife Management Units (E1 and E2) in Essex County and consisted of extensive bogs and softwood swamps, and young, intermediate, and mature forest stands. Elevation ranged from 200 to $1000 \mathrm{~m}$. In higher elevations $(>800 \mathrm{~m})$, species composition was dominated by red spruce (Picea rubens) and balsam fir (Abies balsamea), while intermediate elevations consisted primarily of maple (Acer spp.), birch (Betula spp.), and beech (Fagus grandifolia). Lowland swamp and bog areas were dominated by balsam fir, red spruce, black spruce ( $P$. mariana), poplar (Populus spp.), paper birch (Betula papyrifera), and alder (Alnus spp.). Vermont experiences four distinct seasons, including summer (June-August), fall (September-November), winter (DecemberFebruary), and spring (March-May). Between 2017 and 2019, winter temperatures averaged $-3.81^{\circ} \mathrm{C}$, with an average snowfall ranging between 220 and $250 \mathrm{~cm}$ (NCDC, 2019). During summer months, temperatures averaged $18^{\circ} \mathrm{C}$, with average precipitation ranging between 100 and $110 \mathrm{~cm}$ (NCDC, 2019).

\section{Radio-Collaring}

A helicopter was used to capture and radio-collar 126 moose between 2017 and 2019 (see DeBow et al., in press). Collaring occurred in January of each year under snow conditions that increased visibility and limited potential injury to individual moose. In 2017, 60 moose (30 8-month-old calves, 30 adult female moose) were fixed with Survey Globalstar V7.1 GPS/VHF collars (VECTRONIC Aerospace GmbH, Berlin, Germany) and ear tags. In 2018 and 2019, 36 moose (30 calves and 6 adult female moose) and 30 moose (30 calves) were similarly collared, respectively. Moose were captured throughout the study area, although more moose were fixed with radio-collars in the northern portion. Collars were programmed to send a Global Positioning System (GPS) coordinate every 13-h. We used GPS Plus X software to manage collars and receive location data. All capture, handling, and radio-collaring procedures were reviewed and approved by the University of Vermont Institutional Animal Care and Use Committee (IACUC protocol \#17-035).

\section{Objective 1: First Order Habitat Selection of Adult Female Moose With Multi-Season Occupancy Analysis}

We used dynamic occupancy models to assess first-order habitat selection of female moose during the winter tick questing and winter tick drop-off periods (Design I; Manly et al., 2002). These models allow inference about the occurrence of moose across a collection of spatially identified "sites" or patches, and how patterns of occurrence change through time (MacKenzie et al., 2003; Martin et al., 2009). Dynamic occupancy models can be used to assess first-order habitat selection when patches (resource units) are not considered independent (MacKenzie, 2006). In the original formulation (MacKenzie et al., 2003), the initial probability that a species occupies a sample unit during a defined sampling period defines occupancy $(\mathrm{psi}, \psi)$ ). Thereafter, two additional parameters drive changes in occupancy probability over time: colonization (gamma, $\gamma$ ) and extinction (epsilon, $\varepsilon)$ (MacKenzie et al., 2003). A fourth parameter ( $p$ ) models the detection probability of a species at a site, given presence. Importantly, the parameters of dynamic occupancy models can be modeled as a function of covariates; in our case, those included habitat and landscape conditions related to moose and winter ticks (MacKenzie et al., 2017). 


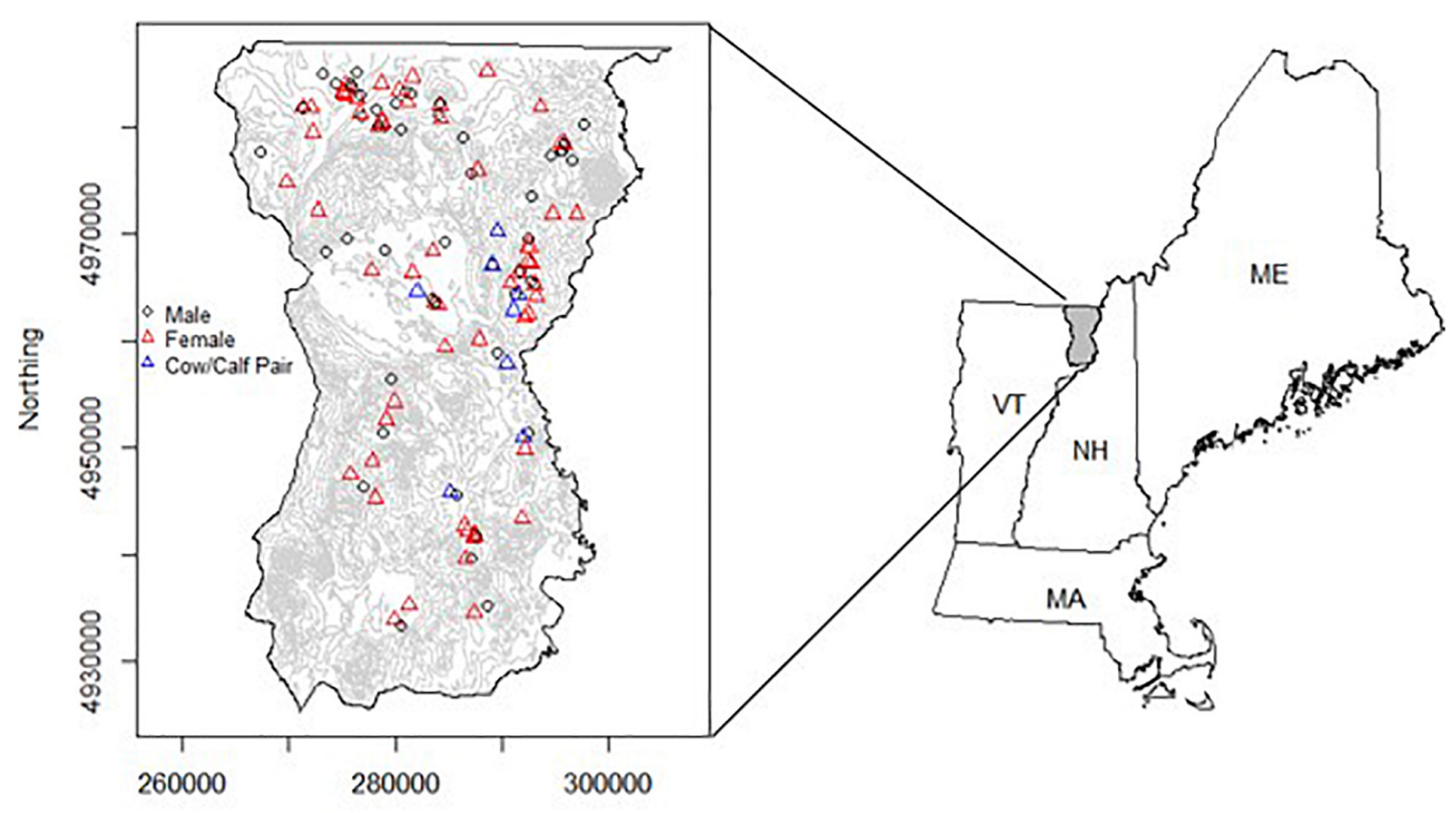

Easting

FIGURE 1 | The location of the study area in northeastern Vermont, United States (1,738 km²), encompassing Essex County (Wildlife Management Unit E). GPS radio-collars were attached to moose (Alces alces) $(n=126)$ in the area and monitored from 2017 to 2019 . The study area was bounded by the Canada-U.S. border to the north, New Hampshire to the east, VT-Route 2 to the south, and VT-Route 114 to the west. Red triangles indicate the capture location for female moose $(n=74)$, while circles indicate where male moose were captured $(n=52)$. Blue triangles show the capture location for adult female moose $(n=10)$ included in the habitat selection and fitness consequences analysis (i.e., objective 2). The map on the right shows the study area in relation to other northeastern states (ME, Maine; $\mathrm{NH}$, New Hampshire; and MA, Massachusetts).

Global Positioning System collar data were filtered into the two primary periods for all female moose captured during the study. For each year, the questing period included the peak 50 days of questing (26 September - 15 November), while the drop-off period spanned from (16 March - 5 May) (Healy et al., 2018). Within each period, data were further subset into two survey periods of equal duration, which allowed us to address detection probability. After considering only female calves and adults within our defined periods, analyses of occupancy were based on 12,210 GPS locations of 74 moose (Figure 1).

We imposed a grid of 1693 patches, each $1 \mathrm{~km}^{2}$, over our study area using the aggregate() function in the $\mathrm{R}$ package, raster (Hijmans and Van Etten, 2012). Encounter histories based on collared moose locations were created for each patch over seven total primary periods (drop-off 2017, questing 2017, dropoff 2018, questing 2018, drop-off 2019, questing 2019, drop-off 2020), each with two secondary survey periods (14 total survey periods). We used the rasterize() function in the raster package to count the number of GPS coordinates that occurred within a grid cell patch in each survey period. The counts were then converted to a binary encounter history (i.e., if the count within a patch was greater than 0 , it was assigned a 1 , otherwise a 0 ). For example, a patch with an encounter history of 11001010 101101 indicated the patch was initially occupied by moose during the first primary period (11, drop-off period of 2017), where moose were detected in both the first and second survey periods. In the second primary period ( 00 , the questing period of 2017), the patch either went locally extinct, or failed to go extinct but moose were undetected in both survey periods. The patch was occupied in the third primary period (10, tick drop-off period of 2018), due to one of two conditions: if the patch was extinct in the previous period, it was re-colonized. If the patch was occupied in the previous primary period but simply undetected, it again failed to go locally extinct. In either case, the species was detected in the first survey but missed in the second survey. The remaining primary periods (10 101101$)$ suggest that the patch remained occupied, but moose were undetected on some surveys.

In the context of first order habitat selection of adult female moose (use of resource units), the assumptions of the multiseason occupancy model were: (1) patches were closed with respect to changes in occupancy within each primary period, and (2) there were no false positive detections (MacKenzie et al., 2004). When the first assumption was not met, we assumed changes in occupancy were random and we re-defined occupancy as "site-use." In the context of occupancy modeling utilizing GPS points across individuals, two additional assumptions were made. First, by including both adult and calf female GPS points, we assumed that a patch occupied by a collared female calf was also occupied by an un-collared, nearby female adult. Further, we assumed autocorrelation among patches was negligible due to the number of sites, the number of moose collared, and their ability to traverse great distances. 
We identified habitat variables of potential importance to moose occupancy (Table 1). These covariates included $30 \mathrm{~m}^{2}$ National Land Cover Data (USGS, 2016a) spatial layers describing land cover types (deciduous forest, coniferous forest, mixed forest, and wetland), $30 \mathrm{~m}^{2}$ layers describing terrain characteristics (elevation and slope) (VCGI, 2002), and $10 \mathrm{~m}^{2}$ lidar (light detection and ranging) variables (USGS, 2016b) characterizing forest age structure (shrub, forage, cover, and canopy). We used the aggregate() function in the raster package to rescale each raster to match the $1 \mathrm{~km}^{2}$ patch resolution for occupancy analysis, where each patch value provided the average of the underlying cells (e.g., Figure 2).

We then performed a principal component analysis (PCA) using the princomp() function in the $\mathrm{R}$ stats package ( $\mathrm{R}$ Core Team, 2018) to account for the complex and often correlated relationships between habitat composition rasters (mean evergreen, deciduous, mixed, and wetland), forest structure rasters (mean canopy, cover, forage, shrub), and mean elevation. Each principal component was influenced differently by the habitat variables; the top three principal components were included as habitat variables in the dynamic occupancy model set.

We used the package, RPresence (Hines, 2006) to evaluate changes in occupancy patterns across patches and through time $[(\operatorname{occMod}())$ function, type $=$ "do.1"]. We created a model set of 24 models (including the intercept model), representing alternative hypotheses that explain changing occupancy patterns through time (Table 2). Each model consisted of four submodels that specified the initial occupancy, detection, colonization, and extinction parameters and related them to resource attributes at a spatial scale of $1 \mathrm{~km}^{2}$. Across all models, the formula predicting initial occupancy $(\psi)$ remained constant $(\sim \mathrm{PC} 1+\mathrm{PC} 2+\mathrm{PC} 3)$, as did the formula predicting detection $(p)$ across the study area $(\sim \mathrm{PC} 1+\mathrm{PC} 2+$ northing + slope + season $)$. The PCA and slope variables in the detection submodel were informed by a
GPS collar bias study in our study area (Blouin et al., in press), where GPS transmission rates were found to be a function of habitat variables and slope. The northing variable was included in the detection submodel because more animals were collared in the northern portion of our study area than in the south. The complexity of the gamma $(\gamma)$ and epsilon $(\varepsilon)$ formulas varied across the model set, from one variable examining the influence of year, to more complex formulas examining the interaction between habitat variables and the season (winter tick questing vs. drop-off), which was of specific interest to test hypotheses that colonization and extinction rates depended on critical winter tick periods. Year was included in most models to account for new animals that were collared each January, potentially affecting both extinction and colonization rates (Table 2).

Models were compared using Akaike information criterion (AIC) (Burnham and Anderson, 2002) to determine a single, best model to predict multi-season occupancy. We used the RPresence (Hines, 2006) function, createAicTable() to rank models and compute model likelihoods. All inferences were made based on the top performing model in the model set.

\section{Objective 2: Fitness Implications of Second-Order Resource Selection Models (RSFs) for Adult Female Moose That Successfully Reared a Calf to Age 1 Versus Those That Did Not}

We developed both logistic regression and negative binomial RSFs to assess second-order habitat selection of adult female moose during the fall questing period, and whether these decisions influenced the survival of calves the following spring (Design II from Manly et al., 2002; see also Thomas and Taylor, 2006). As all individuals were collared in January, this required that we targeted uncollared calves with collared

TABLE 1 | Covariates used to develop multi-season occupancy models for moose (Alces alces) in northeastern Vermont, United States.

\begin{tabular}{|c|c|c|c|c|}
\hline Covariate name & Description & Resolution & Data source & References \\
\hline Shrub & $\begin{array}{l}\text { Proportion of each patch that was defined as "shrub" (vegetation between }>0.02 \text { and } \\
\leq 2.0 \mathrm{~m} \text { ). Defined because of its potential importance to moose as a food source, but } \\
\text { also to winter ticks as they tend to quest (or seek a host) within this height range. }\end{array}$ & $10 \mathrm{~m}^{2}$ & Lidar 2016 & USGS, 2016b \\
\hline Forage & $\begin{array}{l}\text { Proportion of each patch that was defined as potential "forage" (vegetation } \leq 3.0 \mathrm{~m} \text { ) or } \\
\text { vegetation that was within reach of moose. }\end{array}$ & $10 m^{2}$ & Lidar 2016 & USGS, 2016b \\
\hline Cover & $\begin{array}{l}\text { Proportion of each patch that was defined as "cover" (vegetation between }>3.0 \text { and } \\
<6.0 \mathrm{~m} \text { ). }\end{array}$ & $10 m^{2}$ & Lidar 2016 & USGS, 2016b \\
\hline Canopy & $\begin{array}{l}\text { Proportion of each patch that was defined as "canopy" (vegetation }>6.0 \mathrm{~m} \text { ). Defined } \\
\text { because of its potential importance to moose as a source of protection for thermal } \\
\text { stress or shelter during periods of deep snow. }\end{array}$ & $10 m^{2}$ & Lidar 2016 & USGS, 2016b \\
\hline Wetland & $\begin{array}{l}\text { Binary classification defined as "wetland" forest (NLCD emergent and woody wetland } \\
\text { classifications were combined to represent general wetlands). }\end{array}$ & $30 \mathrm{~m}^{2}$ & NLCD 2016 & USGS, 2016a \\
\hline Deciduous & $\begin{array}{l}\text { Binary classification defined as "deciduous" forest ( }>75 \% \text { of the tree species shed } \\
\text { foliage simultaneously in response to seasonal change). }\end{array}$ & $30 m^{2}$ & NLCD 2016 & USGS, 2016a \\
\hline Evergreen & $\begin{array}{l}\text { Binary classification defined as "evergreen" forest (> } 75 \% \text { of the tree species maintain } \\
\text { their leaves all year). }\end{array}$ & $30 m^{2}$ & NLCD 2016 & USGS, 2016a \\
\hline Mixed & $\begin{array}{l}\text { Binary classification defined as "mixed" forest (Neither deciduous nor evergreen species } \\
\text { are }>75 \% \text { of total tree cover). }\end{array}$ & $30 \mathrm{~m}^{2}$ & NLCD 2016 & USGS, 2016a \\
\hline Elevation & A measure of the average elevation (m). & $30 m^{2}$ & VCGI 2002 & VCGI, 2002 \\
\hline Slope & A measure of the average slope (degrees). & $30 m^{2}$ & VCGI 2002 & VCGI, 2002 \\
\hline
\end{tabular}



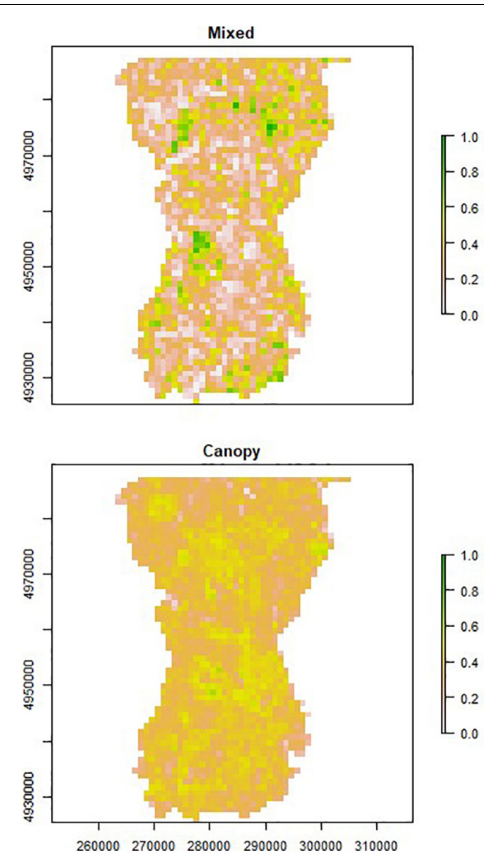
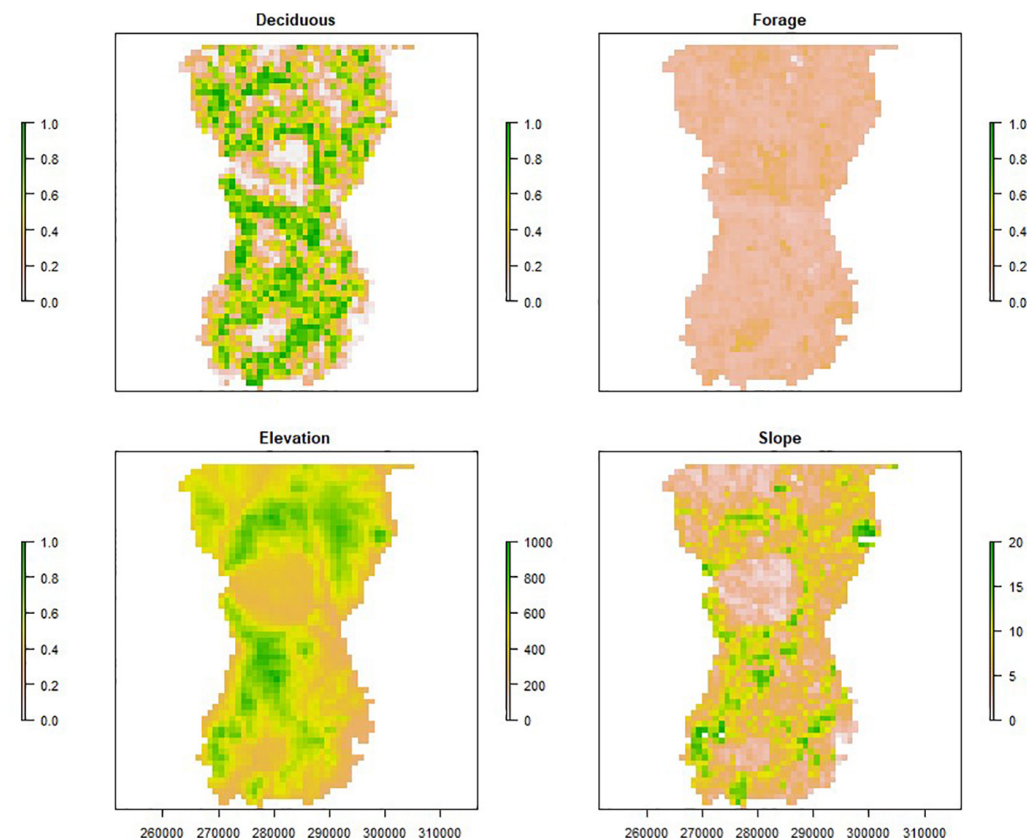

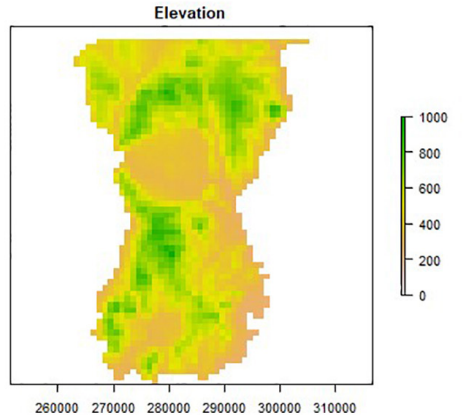

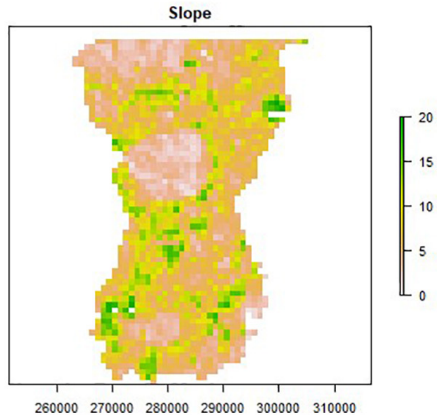

FIGURE 2 | Distribution of six important habitat variables for moose (Alces alces) in northeastern Vermont, United States. Measures include proportion for the structural components (e.g., canopy and forage; represented by lidar data) and composition variables (e.g., mixed and deciduous forest cover; represented by NLCD data), meters for elevation, and degrees for slope. Cell size is $1 \mathrm{~km}^{2}$ and axes include UTM Easting and Northing coordinates.

adult female moose, allowing inference of where that calf was with its mother during the fall questing period, when acquiring winter ticks. We were successful in collaring 10 calves, providing a small dataset of adult female-calf pairs in which the fate of the calf was known $(0=$ calf died prior to first birthday, 1 = calf survived to first birthday) as well as the GPS locations of their mothers during the fall questing period. Two RSFs were estimated: one for adult females that successfully reared offspring to age 1 , and one for those whose calves perished prior to age 1 .

We used the same base rasters and approach as for Objective 1 (Table 1) but added an additional $30 \mathrm{~m}^{2}$ raster that provided the probability of GPS transmission rate, given each pixel's habitat, elevation, and slope (Blouin et al., in press). Unlike the first objective where analysis was at the $1 \mathrm{~km}^{2}$ resolution, we gridded the rasters at $200 \mathrm{~m}^{2}$ resolution for a more fine-scale assessment of selection using the aggregate() function in the raster package. This scale was selected because it was fine enough to discriminate habitat conditions among patches, yet coarse enough to accommodate multiple GPS points within a patch (Boyce, 2006). To account for all habitat variables while avoiding issues associated with modeling highly correlated variables, we performed a Principal Component Analysis with the princomp() function in the $\mathrm{R}$ package, stats ( $\mathrm{R}$ Core Team, 2018). Each component represented a different combination of the nine input variables (mean evergreen, deciduous, mixed, wetland, canopy, cover, forage, shrub, and elevation). The four top components accounting for the majority of the total variation of data were selected to represent habitat composition, structure and terrain variables.
For each adult female, we counted the number of GPS points that fell within each $200 \mathrm{~m}^{2}$ raster patch during the fall questing period (September 26 - November 15); unused patches were assigned a 0 . For each adult female, we conducted 1000 bootstrap trials wherein each trial's dataset consisted of 10,000 randomly sampled unused patches and all patches that included any GPS locations. For the logistic regression RSFs, data were collapsed into used/unused binary classifications. The logistic regression model for each female was "used PC1 + PC2 + PC3 + PC4" with a logistic link function, while the negative binomial models had the form "counts PC1 + PC2 + PC3 + PC4" with a $\log$ link function. Models were run with the $g \operatorname{lm}()$ and $g \operatorname{lm} . n b()$ functions, respectively ( $\mathrm{R}$ Core Team, 2018). In both models, data points were weighted by the inverse of the patch's GPS transmission rate, which provided the probability that a GPS signal would be detected given the patch's habitat conditions, slope, and elevation (Blouin et al., in press). For each model and trial, model coefficients were stored, and population-level RSFs were based on aggregated coefficients across trials.

\section{RESULTS}

\section{Objective 1: First-Order Habitat Selection of Adult Female Moose With Multi-Season Occupancy}

The $1693\left(1 \mathrm{~km}^{2}\right)$ patches covering our study area exhibited differences in forest composition, forest structure, and elevation (Figure 2). The encounter histories for each patch identified the 
TABLE 2 | Occupancy models $(n=24)$ analyzed for female moose (Alces alces; $n=74)$ in northeastern Vermont, United States.

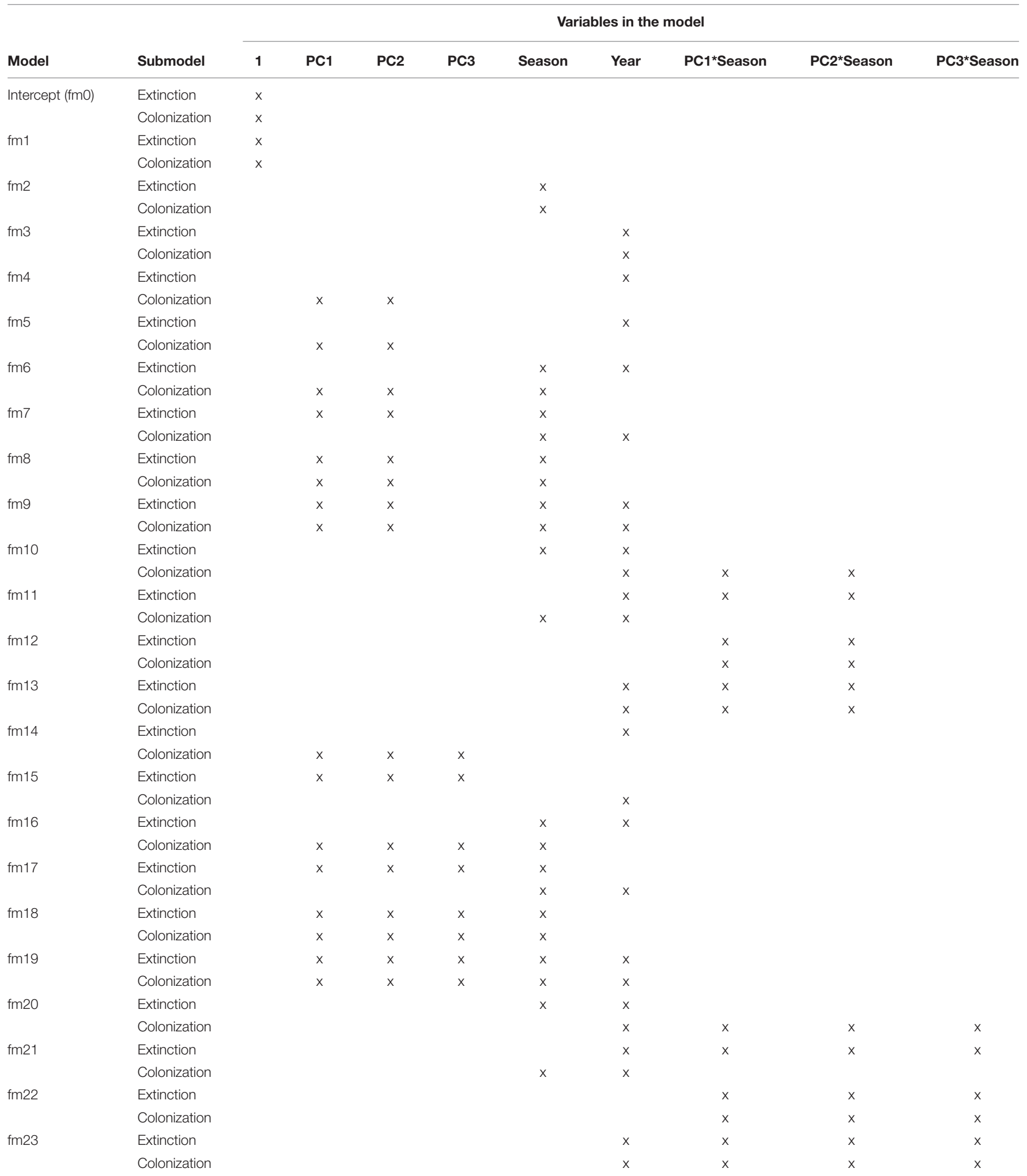

Models include combinations of variables defined by three PCA variables (PC1, PC2, PC3) that accounted for 72\% of total variance. Each formula describes how colonization probability and extinction probability were modeled as a function of the different resources within each PCA variable. Seasons related to tick behavior and included 'questing' in the fall and 'drop-off' in the spring. The study occurred across a three-year period (2017-2019). An " $x$ " marks the combination of each variable included in a model. 
locations of collared female moose during the primary questing and drop-off periods (Figure 3). More patches were occupied during the tick questing periods than drop-off periods: mean patches occupied by moose during the questing period was 468 (naïve occupancy $=0.28$ ), while mean patches occupied during the drop-off period was 409 (naïve occupancy $=0.24$ ). This pattern likely reflects moose movement behavior during the fall breeding season.

The PCA resulted in three principal components describing $72 \%$ of the total variance of the habitat variables (Table 3 ). PC1 was positively influenced by forage/shrub/cover structure and wetland/evergreen composition (i.e., as PC1 increases, forage/shrub/cover and wetland/evergreen forest increase), and negatively influenced by deciduous forest, and to a lesser extent, the canopy structure and elevation. PC2 was positively influenced by mixed/evergreen forests that was more mature in structure and negatively influenced by young (forage/shrub) deciduous forests and wetlands. Finally, PC3 was positively influenced by canopy structure and evergreen/wetland forests and negatively influenced by mixed forest and elevation (Table 3 and Figure 4). The spatial variation of the PC scores and their meanings can be traced back to the original variables (Figure 2).

For female moose, the top model for predicting shifting occupancy patterns across winter tick questing and drop-off periods was model 23 (Table 4). As with all candidate models, initial occupancy for the top model was a function of PC1, PC2, and PC3 and detection was a function of PC1, PC2, northing, slope, and season. Extinction and colonization probabilities for

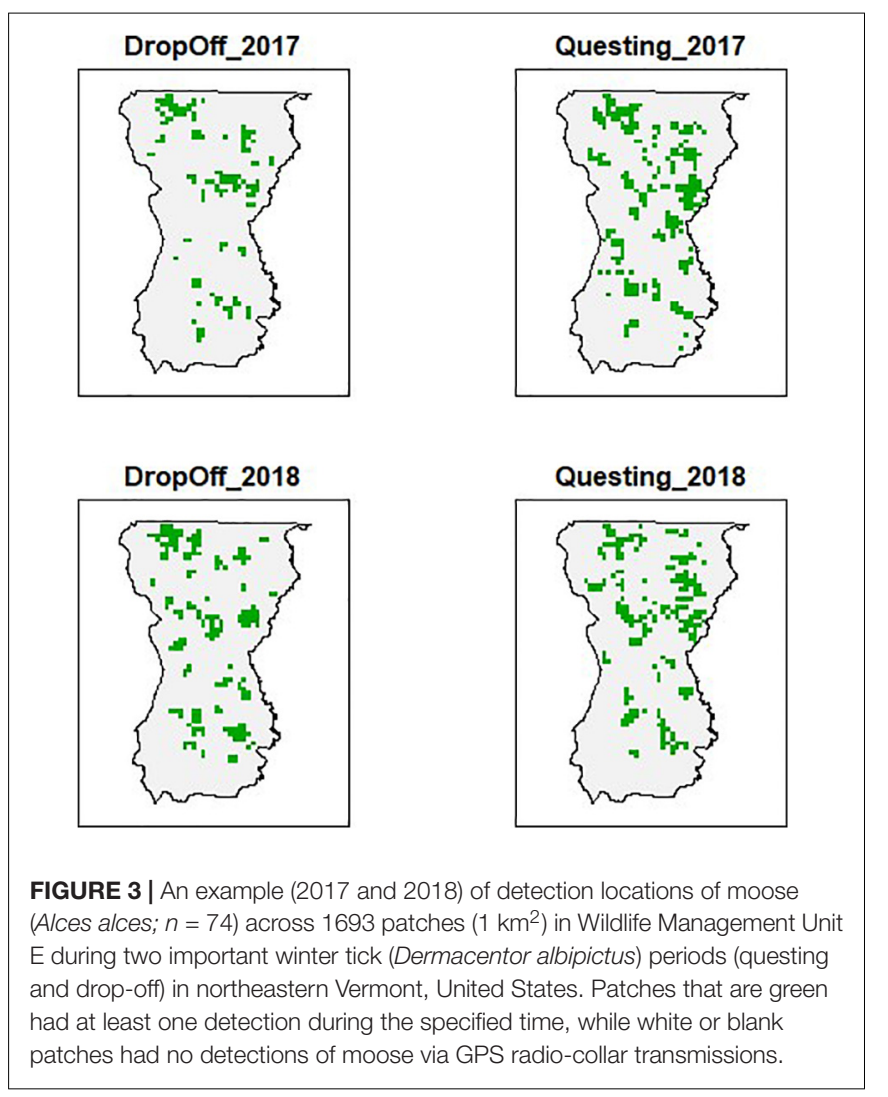

the top model were a function of the interaction between PC1 and season, PC2 and season, PC3 and season, and year. The top model carried virtually all the weight in the model set; no other models were competitive with $\triangle$ AIC scores exceeding 18.0 (Table 4). The intercept model, in which parameters were modeled as constants without covariates, had a $\triangle$ AIC score of 223.27 and a model weight of 0 (Table 4).

The top model estimated 28 parameters (Table 5). For initial occupancy, PC2 had a strong positive effect and PC1 had a slight positive effect, meaning that during the initial primary period (2017 fall drop-off period), the probability of occupancy increased as the proportion of structurally diverse (canopy, cover, forage, and shrub), mixed and evergreen forest increased (Figures 4, 5A). For detection, moose had a higher probability of being detected in the northern part of our study area and where the slope angle was relatively low (Table 4 and Figure 5B). Probability of detection was also higher during the questing period and in patches comprised of more young deciduous forest and less mature evergreen or mixed forest (i.e., patches with lower PC2 scores, Figure 5B).

Extinction rates of any given season describe the probability that patches that were occupied in the previous season become locally extinct and varied between questing and drop-off seasons (Figure 5). From the fall questing period to the spring drop-off period, patch extinction rates were negatively related to PC2 and positively related to PC3 (Figure 5C, top panel); patches that were occupied during fall questing but went extinct during the spring drop-off period were characterized by higher proportions of mature (canopy) evergreen forests and wetland habitats at lower elevations (Figures 4, 6A). Patches on the landscape that failed to go extinct (i.e., remained occupied) between the fall questing and spring drop-off periods were characterized by higher proportions of young (shrub/forage) mixed or deciduous forests at higher elevations (Figures 4, 6A). In contrast, from the spring drop-off to the fall questing period, patch extinction rates were weakly driven by PC3 only, and overall extinction probabilities were low (Figure 5C, bottom panel, Figure 6B). The few patches that were occupied in spring but went locally extinct in the fall were characterized by higher proportions of mature (canopy) evergreen forests and wetland habitats at lower elevations (Figure 6B). Patches on the landscape that failed to go extinct (or remained occupied) during the fall questing period were characterized by higher proportions of young (shrub/forage) deciduous or mixed forests across the elevation gradient.

Colonization rates of any given season describe the probability that patches that were unoccupied in the previous season became locally colonized and varied between questing and drop-off seasons (Figure 5). From the fall questing period to the spring drop-off period, patch colonization rates were negatively related to both PC1 and PC3 (Figure 5D, top panel); patches that were unoccupied during fall questing but were colonized during the spring drop-off period had higher proportions of young (shrub/forage) mixed forest at greater elevations (Figure 6C). Patches that failed to be colonized (remained unoccupied) between the fall questing and spring drop-off periods were characterized by higher 
TABLE 3 | A Principal Component Analysis of variables considered when analyzing multi-season occupancy data for moose (Alces alces) in northeastern Vermont, United States.

\begin{tabular}{|c|c|c|c|c|c|c|c|c|c|c|}
\hline Objective & Variable & Comp.1 & Comp.2 & Comp.3 & Comp.4 & Comp.5 & Comp.6 & Comp.7 & Comp.8 & Comp.9 \\
\hline \multirow[t]{10}{*}{1} & Cumulative proportion & 0.38 & 0.61 & 0.72 & 0.82 & 0.89 & 0.95 & 0.99 & 1.00 & 1.00 \\
\hline & Evergreen & 0.30 & 0.38 & 0.31 & 0.09 & 0.64 & 0.24 & 0.04 & 0.44 & 0.00 \\
\hline & Deciduous & -0.41 & -0.32 & -0.02 & -0.35 & -0.09 & 0.27 & -0.31 & 0.65 & 0.01 \\
\hline & Mixed & 0.11 & 0.48 & -0.48 & 0.32 & -0.48 & 0.11 & 0.14 & 0.41 & 0.02 \\
\hline & Wetland & 0.34 & -0.14 & 0.55 & -0.20 & -0.43 & -0.31 & 0.39 & 0.32 & -0.01 \\
\hline & Canopy & -0.25 & 0.38 & 0.43 & -0.14 & -0.33 & 0.62 & 0.05 & -0.31 & 0.02 \\
\hline & Cover & 0.29 & 0.41 & 0.01 & -0.42 & -0.14 & -0.28 & -0.67 & -0.06 & -0.17 \\
\hline & Forage & 0.48 & -0.18 & -0.19 & -0.25 & -0.04 & 0.30 & -0.06 & -0.09 & 0.73 \\
\hline & Shrub & 0.44 & -0.27 & -0.24 & -0.20 & -0.01 & 0.43 & 0.14 & -0.08 & -0.66 \\
\hline & Elevation & -0.23 & 0.30 & -0.30 & -0.66 & 0.21 & -0.16 & 0.51 & -0.02 & 0.04 \\
\hline \multirow[t]{10}{*}{2} & Cumulative Proportion & 0.33 & 0.55 & 0.67 & 0.78 & 0.87 & 0.94 & 0.99 & 1.00 & 1.00 \\
\hline & Evergreen & 0.15 & 0.42 & 0.54 & 0.19 & 0.53 & 0.03 & 0.11 & 0.44 & 0.00 \\
\hline & Deciduous & -0.35 & -0.46 & -0.03 & 0.27 & -0.02 & 0.22 & -0.45 & 0.59 & 0.00 \\
\hline & Mixed & 0.05 & 0.47 & -0.57 & -0.40 & -0.07 & 0.21 & 0.02 & 0.49 & 0.02 \\
\hline & Wetland & 0.35 & -0.07 & 0.32 & 0.08 & -0.74 & 0.07 & 0.32 & 0.33 & -0.01 \\
\hline & Canopy & -0.33 & 0.36 & 0.25 & 0.06 & -0.21 & 0.73 & -0.14 & -0.32 & 0.00 \\
\hline & Cover & 0.25 & 0.42 & -0.07 & 0.37 & -0.25 & -0.33 & -0.64 & -0.07 & -0.17 \\
\hline & Forage & 0.53 & -0.12 & -0.14 & 0.17 & 0.13 & 0.30 & -0.15 & -0.10 & 0.72 \\
\hline & Shrub & 0.49 & -0.22 & -0.16 & 0.10 & 0.21 & 0.41 & 0.02 & -0.07 & -0.67 \\
\hline & Elevation & -0.21 & 0.14 & -0.40 & 0.74 & 0.00 & 0.00 & 0.48 & -0.01 & 0.02 \\
\hline
\end{tabular}

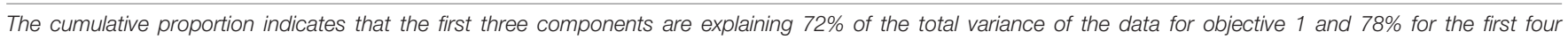
components in objective 2.
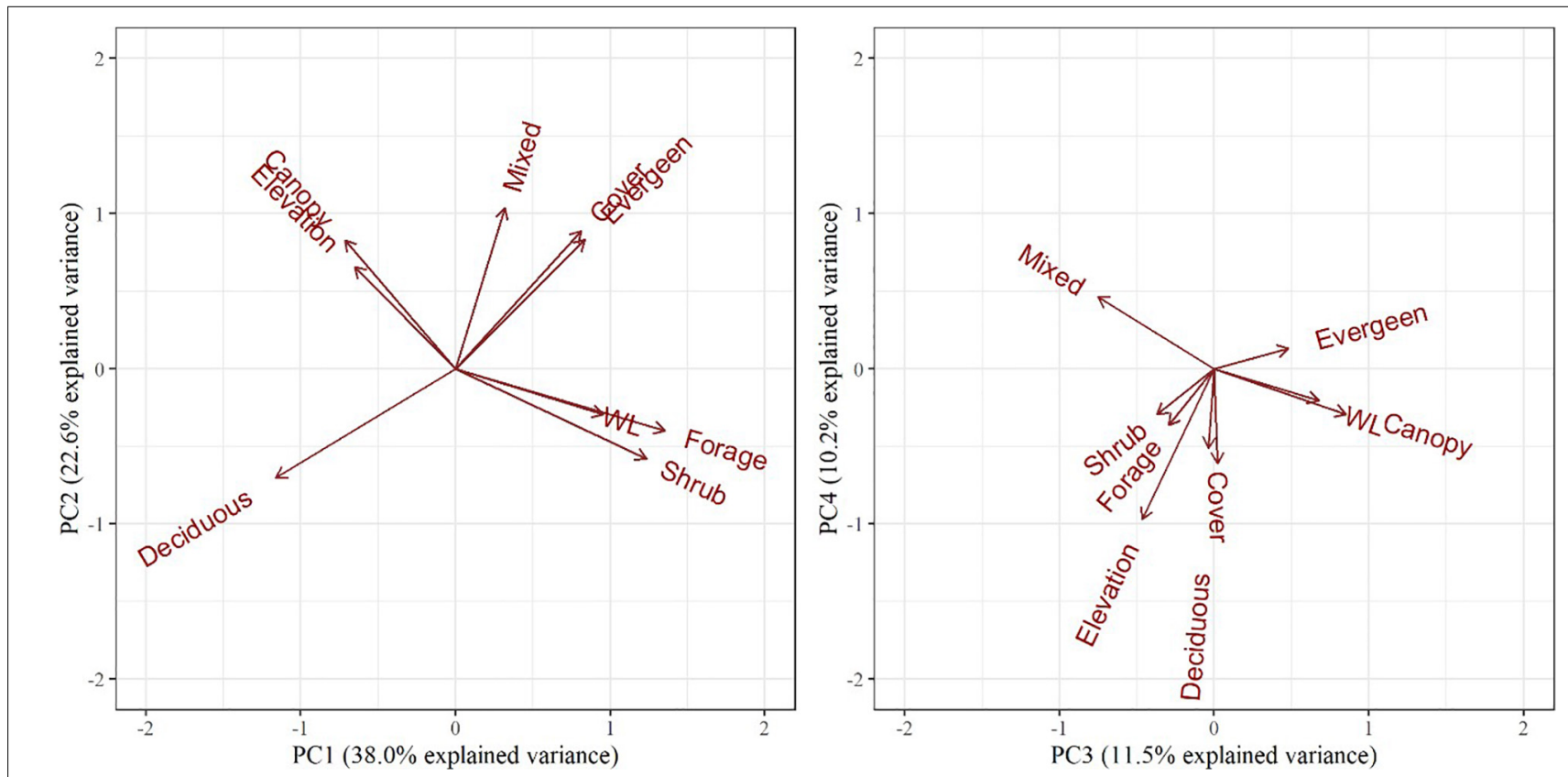

FIGURE 4 | Biplots of the top four principal components for objective 1 examining habitat selection and occupancy. The biplot explains habitat variables selected by female moose (Alces alces; $n=74$ ) in northeastern Vermont, United States. The influence of each habitat variable on the components is expressed by the length and direction of the arrows (i.e., loadings).

proportions of mature evergreen forests and wetlands at lower elevations. In contrast, from the spring drop-off to the fall questing period patch colonization rates were largely driven by PC3 (Figure 5D, lower panel). Patches that had higher probabilities of being colonized from the spring drop-off to the fall questing period had higher proportions of mature (canopy) deciduous and evergreen forests and wetland habitats at lower elevations. Lastly, patches that failed to be colonized (remained unoccupied) from the spring drop-off to the fall questing period were characterized by higher proportions early 
TABLE 4 | Model selection results of multi-season occupancy data for female moose (Alces alces; $n=74)$ in northeastern Vermont, United States.

\begin{tabular}{|c|c|c|c|c|c|}
\hline Model & AIC & $\Delta \mathrm{AIC}$ & NLL & $K$ & Weight \\
\hline $\mathrm{fm} 23-\operatorname{gam}\left(\mathrm{PC} 1^{*} \mathrm{~S}+\mathrm{PC} 2^{\star} \mathrm{S}+\mathrm{PC}^{\star} \mathrm{S}\right) \operatorname{eps}\left(\mathrm{PC} 1^{*} \mathrm{~S}+\mathrm{PC} 2^{\star} \mathrm{S}+\mathrm{PC} 3^{\star} \mathrm{S}\right)$ & 712.95 & 0 & 656.95 & 28 & 1 \\
\hline fm22 - gam(S + YT)eps $\left(P C 1^{\star} S+P C 2^{\star} S+P C 3^{\star} S+Y T\right)$ & 731.69 & 18.74 & 679.69 & 26 & 0 \\
\hline $\mathrm{fm} 17-\operatorname{gam}(\mathrm{PC} 1+\mathrm{PC} 2+\mathrm{PC} 3+\mathrm{S}) \mathrm{eps}(\mathrm{S}+\mathrm{YT})$ & 731.88 & 18.93 & 695.88 & 18 & 0 \\
\hline $\mathrm{fm} 19-\operatorname{gam}(\mathrm{PC} 1+\mathrm{PC} 2+\mathrm{PC} 3+\mathrm{S}) \mathrm{eps}(\mathrm{PC} 1+\mathrm{PC} 2+\mathrm{PC} 3+\mathrm{S})$ & 732.52 & 19.57 & 688.52 & 22 & 0 \\
\hline$f m 21-\operatorname{gam}\left(P C 1^{\star} S+P C 2^{\star} S+P C 3^{\star} S+Y T\right) e p s(S+Y T)$ & 735.22 & 22.27 & 691.22 & 22 & 0 \\
\hline $\mathrm{fm} 20-\operatorname{gam}(\mathrm{PC} 1+\mathrm{PC} 2+\mathrm{PC} 3+\mathrm{S}+\mathrm{YT}) \mathrm{eps}(\mathrm{PC} 1+\mathrm{PC} 2+\mathrm{PC} 3+\mathrm{S}+\mathrm{YT})$ & 736.57 & 23.62 & 692.57 & 22 & 0 \\
\hline $\mathrm{fm} 15-$ gam $(\mathrm{PC} 1+\mathrm{PC} 2+\mathrm{PC} 3+\mathrm{S}) \mathrm{eps}(\mathrm{S}+\mathrm{YT})$ & 745.25 & 32.3 & 713.25 & 16 & 0 \\
\hline$f m 13-\operatorname{gam}\left(P C 1^{*} S+P C 2^{*} S\right) e p s\left(P C 1^{*} S+P C 2 * S\right)$ & 753.71 & 40.76 & 705.71 & 24 & 0 \\
\hline $\mathrm{fm} 10-\operatorname{gam}(\mathrm{PC} 1+\mathrm{PC} 2+\mathrm{S}+\mathrm{YT}) \mathrm{eps}(\mathrm{PC} 1+\mathrm{PC} 2+\mathrm{S}+\mathrm{YT})$ & 754.75 & 41.8 & 714.75 & 20 & 0 \\
\hline fm18 - gam(S + YT)eps(PC1 + PC2 + PC3 + S) & 755.57 & 42.62 & 715.57 & 20 & 0 \\
\hline $\mathrm{fm} 7-\operatorname{gam}(P C 1+P C 2+\mathrm{S}) \operatorname{eps}(\mathrm{S}+\mathrm{YT})$ & 760.74 & 47.79 & 726.74 & 17 & 0 \\
\hline $\mathrm{fm} 11-\operatorname{gam}\left(P C 1^{\star} \mathrm{S}+\mathrm{PC} 2^{*} \mathrm{~S}+\mathrm{YT}\right) \mathrm{eps}(\mathrm{S}+\mathrm{YT})$ & 763.68 & 50.73 & 723.68 & 20 & 0 \\
\hline $\mathrm{fm} 9-\operatorname{gam}(\mathrm{PC} 1+\mathrm{PC} 2+\mathrm{S}) \mathrm{eps}(\mathrm{PC} 1+\mathrm{PC} 2+\mathrm{S})$ & 765.31 & 52.36 & 725.31 & 20 & 0 \\
\hline fm3 - gam(YT)eps(YT) & 768.73 & 55.78 & 740.73 & 14 & 0 \\
\hline $\mathrm{fm} 5-\operatorname{gam}(\mathrm{PC} 1+\mathrm{PC} 2) \operatorname{eps}(\mathrm{YT})$ & 770.26 & 57.31 & 740.26 & 15 & 0 \\
\hline fm12 - gam(S + YT)eps(PC1*S + PC2*S) & 775.07 & 62.12 & 731.07 & 22 & 0 \\
\hline fm6 - gam(YT)eps(PC1 + PC2) & 783.36 & 70.41 & 749.36 & 17 & 0 \\
\hline fm2 - gam(S)eps(S) & 784.34 & 71.39 & 756.34 & 14 & 0 \\
\hline fm16 - gam(YT)eps(PC1 + PC2 + PC3) & 784.99 & 72.04 & 748.99 & 18 & 0 \\
\hline fm4 - gam(Y)eps(Y) & 786.13 & 73.18 & 756.13 & 15 & 0 \\
\hline $\mathrm{fm} 8-\operatorname{gam}(\mathrm{S}+\mathrm{YT}) \mathrm{eps}(\mathrm{PC} 1+\mathrm{PC} 2+\mathrm{S})$ & 786.97 & 74.02 & 750.97 & 18 & 0 \\
\hline $\mathrm{fm} 14-\operatorname{gam}\left(\mathrm{PC} 1^{\star} \mathrm{S}+\mathrm{PC} 2^{\star} \mathrm{S}+\mathrm{YT}\right) \operatorname{eps}\left(\mathrm{PC} 1^{\star} \mathrm{S}+\mathrm{PC} 2^{\star} \mathrm{S}+\mathrm{YT}\right)$ & 787.64 & 74.69 & 755.64 & 16 & 0 \\
\hline fm1 - gam(.)eps(.) & 789.15 & 76.2 & 765.15 & 12 & 0 \\
\hline
\end{tabular}

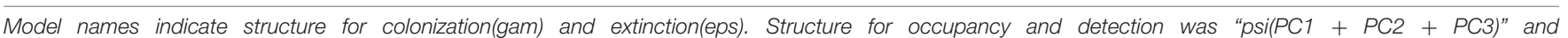

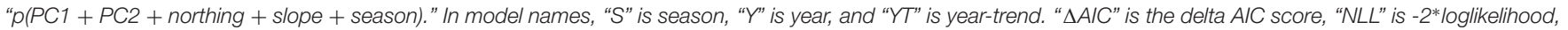
" $K$ " is the number of parameters, and "Weight" is the model weight.

successional (shrub/forage) mixed and deciduous habitats at lower elevations (Figure 6D).

To summarize the complex dynamic occupancy model results, patch extinction and colonization rates between the fall questing and spring drop-off periods were driven by at least 2 principal components with strong effect sizes, while a single component with smaller effect sizes influenced rates from the spring drop-off to the fall questing period. Further, patches where colonization was high and extinction low from the fall questing period to the spring drop-off period (highest probability of female moose occupancy) had higher proportions of young (shrub/forage) mixed forest at greater elevations (Figures 6A,C). In contrast, patches where colonization was high and extinction low from the spring drop-off to the fall questing period were characterized by higher proportions of both mature (canopy) and young (shrub/forage) deciduous or mixed forests and wetland habitats at low elevations (Figures 6B,D).

\section{Objective 2: Fitness Implications of Second-Order Resource Selection Models (RSFs) for Adult Female Moose That Successfully Reared a Calf to Age 1 Versus Those That Did Not}

The $200 \mathrm{~m}^{2}$ pixel resolution resulted in 42,691 patches for RSF analysis. The PCA resulted in four principal components describing $78 \%$ of the total variance of the habitat variables (Table 3). PC1 was positively influenced by younger (shrub/forage) wetland habitats (i.e., as PC1 increases, forage/shrub and wetland forest increase), and negatively influenced by the proportion of mature (canopy lidar classifications) deciduous forest. PC2 was positively influenced by mixed and evergreen forests that were more mature in structure and negatively influenced by early succession (shrub/forage) deciduous forests. PC3 was positively influenced by mature (canopy) evergreen forests and wetland habitats and negatively influenced by mixed forests and elevation. PC4 was positively influenced by higher elevation deciduous and evergreen forests of all age classes and negatively influenced the mixed forest composition (Table 3 and Figure 7).

Both the logistic regression RSFs and negative binomial RSFs indicated strong differences in habitat selection between female moose whose calves survived to their first birthday ( $\sim 18$ May; $n=5)$ vs. died $(n=5)$ (Table 6 and Figure 8). In general, female moose with calves that survived exhibited much less variation in how they selected PC2 than those with calves that died (Figure 8). Specifically, adult females with surviving calves had a consistent, slightly negative response to PC2, while females with non-surviving calves showed variable responses to PC2. Most noticeably, adult females with surviving calves did not respond or had slightly positive responses to PC3 and had negative responses to PC4, in contrast to adults with non-surviving calves who showed negative responses to PC3 and no response to PC4. These patterns are consistent across both RSF models (logistic 
TABLE 5 | Regression coefficient values from the top-ranking dynamic occupancy model (fm23) explaining initial occupancy, detection, colonization, and extinction probabilities in relation to habitat variables (principal components), terrain, season, or year for moose (Alces alces, $n=74$ ) in northeastern Vermont, United States.

\begin{tabular}{|c|c|c|c|}
\hline Submodel & Parameter & Estimate & $S E$ \\
\hline \multirow[t]{4}{*}{ Occupancy } & Intercept & -0.712 & 0.077 \\
\hline & PC1 & 0.063 & 0.036 \\
\hline & PC2 & 0.113 & 0.050 \\
\hline & PC3 & 0.031 & 0.062 \\
\hline \multirow[t]{6}{*}{ Detection } & Intercept & -0.730 & 0.053 \\
\hline & PC1 & 0.049 & 0.022 \\
\hline & PC2 & -0.119 & 0.023 \\
\hline & Northing & 0.291 & 0.041 \\
\hline & Slope & -0.150 & 0.044 \\
\hline & Season & 0.455 & 0.072 \\
\hline \multirow[t]{9}{*}{ Colonization } & Intercept & -2.982 & 0.569 \\
\hline & PC1 & -0.603 & 0.229 \\
\hline & Season & 1.752 & 0.728 \\
\hline & PC2 & -0.060 & 0.157 \\
\hline & PC3 & -1.804 & 0.467 \\
\hline & Year & -0.510 & 0.108 \\
\hline & PC1*Season & 0.556 & 0.248 \\
\hline & PC2*Season & 0.080 & 0.196 \\
\hline & PC3*Season & 2.241 & 0.430 \\
\hline \multirow[t]{9}{*}{ Extinction } & Intercept & -1.264 & 0.268 \\
\hline & PC1 & -0.115 & 0.049 \\
\hline & Season & -0.928 & 0.366 \\
\hline & PC2 & -0.148 & 0.074 \\
\hline & PC3 & 0.359 & 0.079 \\
\hline & Year & 0.013 & 0.107 \\
\hline & $\mathrm{PC}^{*}{ }^{\star}$ Season & 0.132 & 0.126 \\
\hline & PC2*Season & 0.165 & 0.226 \\
\hline & $\mathrm{PC}^{\star}{ }^{\star}$ Season & -0.137 & 0.188 \\
\hline
\end{tabular}

and negative binomial) but are more apparent in the negative binomial RSF (Figure 8).

Component loadings indicate that adult female moose whose offspring survived to their first birthday selected habitats during the fall questing period with higher proportions of young (shrub/forage) deciduous forests, but also selected habitats with higher proportions of mature (canopy) evergreen or mixed forests and wetlands at lower elevations (Figures 7, 9). Adult female moose whose offspring perished prior to their first birthday were less selective of young (shrub/forage) deciduous forests, instead selecting habitats with higher proportions of young mixed forests at higher elevations during the fall tick questing period (Figures 7, 9).

\section{DISCUSSION}

Winter tick infestations have significantly impacted moose populations in Vermont and the surrounding region (Jones et al., 2019; DeBow et al., in press). Observations of declining populations spurred research on mortality and productivity of moose across the region. Since 2014, >500 adult females and calves have been fixed with radio-collars regionally (Vermont, New Hampshire, Maine, United States) (Jones et al., 2019; Ellingwood et al., 2020; Pekins, 2020; DeBow et al., in press). These studies showed low observed birth rates and reoccurring epizootic mortality due to winter tick infestations ( 5 of 6 years between 2014 and 2019) (Jones et al., 2019; Ellingwood et al., 2020; Pekins, 2020; DeBow et al., in press). Research suggests there are three main factors typically influencing the severity of winter tick infestations - the density of the host (moose) (Pekins, 2020), favorable conditions for winter tick survival (i.e., shorter winters) (Samuel, 2007), and the overlap of moose habitat use during two critically important winter tick life periods (i.e., questing and drop-off periods) (Healy et al., 2018; Pekins, 2020).

To better understand the winter tick-moose cycle and the influence of seasonal overlap, Healy et al. (2018) examined thirdorder habitat selection of moose during the critical tick fall questing and spring drop-off periods. Results showed that moose selected optimal 4-16-year-old forest openings relative to their availability within their home ranges across both the questing and the drop-off periods. This illustrates that once home ranges are established, optimal habitats are often re-used between the tick questing and tick-drop off periods, promoting the life cycle of the winter tick within established home ranges.

Our study of first and second-order habitat selection, along with the fitness consequences of selection, builds on the findings of Healy et al. (2018), while addressing other factors that may also be influencing the cycle and impacting moose fitness. Firstorder habitat selection analysis at the landscape scale revealed that moose were more widespread in their occupancy during the fall questing period versus the early spring drop-off period, and patches with higher proportions of young (shrub/forage) mixed forest at greater elevations had the highest probability of occupancy during the spring tick drop-off period. As moose evolved to lose considerable body mass during the winter months (particularly more severe ones), it follows that habitat use would be more constrained during the late-winter/early-spring dropoff period compared to fall (Schwartz et al., 1988). Furthermore, significant protein loss due to heavy tick infestations would likely restrict habitat use during the late winter months (Jones et al., 2019; Pekins, 2020; Rosenblatt et al., in press). Due to the poor condition of moose by the drop-off period, moose may be seeking swollen buds of young vegetation during the early spring greenup to regain the energy lost over the winter months (Schwartz and Renecker, 2007; Pekins, 2020).

Second-order habitat selection analyses during the fall questing period showed a clear pattern in habitat selection by female moose whose offspring survived versus those that died. For calves of collared adults that perished, the cause of death was determined to be serous atrophy of fat, which is a common consequence of substantial tick infestations. Adult female moose whose offspring perished selected patches during the questing period that were characterized by higher proportions of young (shrub/forage) mixed forest at higher elevations (areas with the highest probability of occupancy during the spring drop-off period; Figures 6A,C). That is, their questing habitat selection matched the first-order models of selection for the population during the spring drop-off period, similar to Healy et al.'s (2018) 


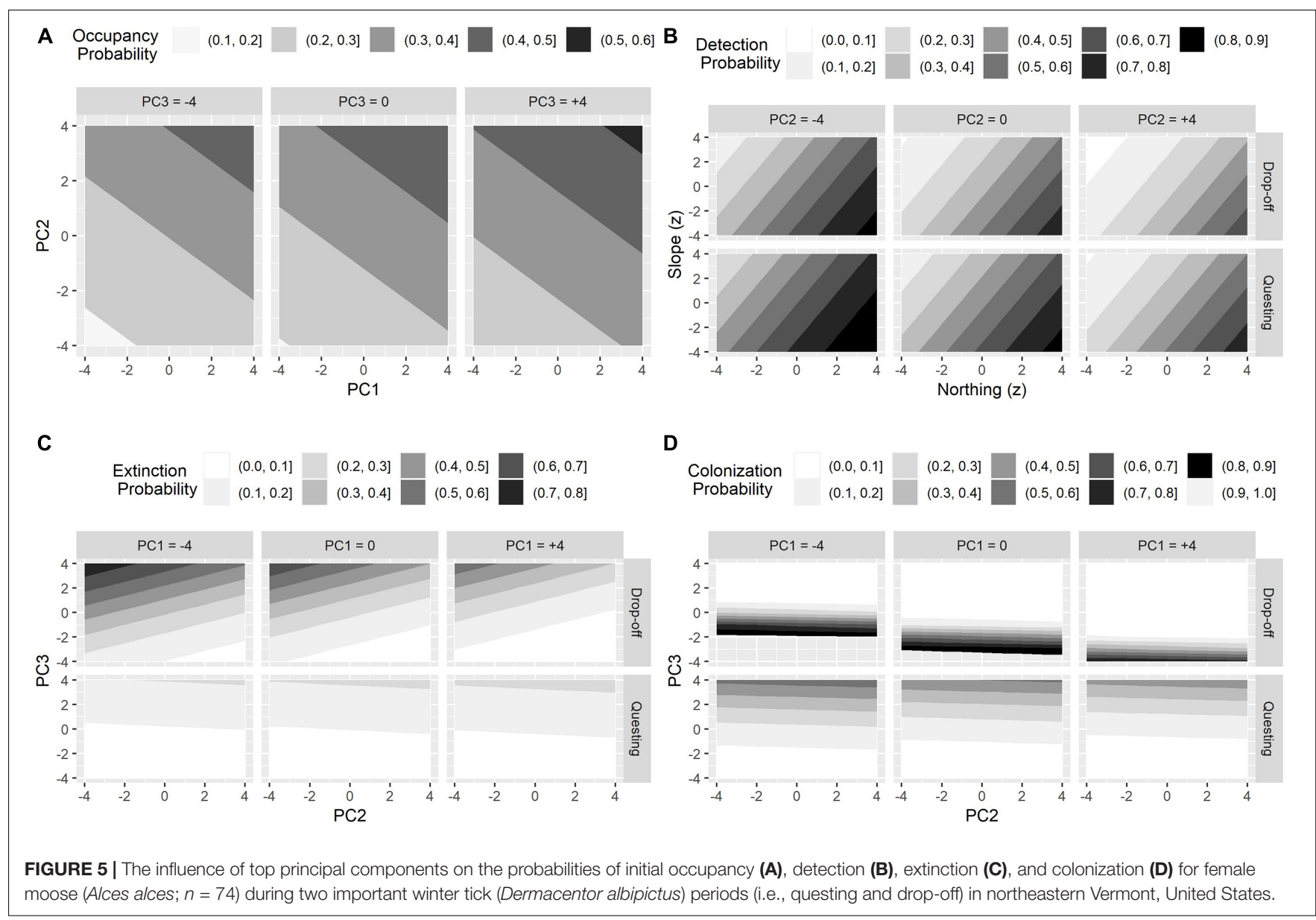

conclusions. In contrast, adult female moose whose offspring survived showed selection patterns characterized by young (shrub/forage) deciduous habitats, while also selecting habitats with higher proportions of mature (canopy) evergreen forests and wetlands at lower elevations, i.e., their second-order habitat selection patterns deviated from the overall first-order patterns described by the multi-season occupancy analysis.

Why are adult female moose with calves that survived selecting areas differently than adult female moose with calves that perished? Habitat selection theory suggests that organisms choose habitats that maximize fitness, and that fitness often declines with increasing density (Fretwell, 1969; Rosenzweig, 1981). Moose may trade patches of more optimal habitats on the landscape for more suboptimal patches based on several factors, including energy, time, risk of injury due to competition, and predation risk (Dussault et al., 2005; Doligez et al., 2008). Alternatively, habitat selection may be driven primarily by cues identifying suitable habitats acquired during early years as a calf (imprinting) or later (learned), that ultimately prove beneficial to their fitness (Cederlund et al., 1987; Doligez et al., 2008). Whatever the reason, natural selection is favoring female adults who selected habitats with higher proportions of mature (canopy) evergreen forests and wetlands at lower elevations during the fall questing period.
Locations where ticks drop off in spring determine where they will quest in the fall. The abundance of questing winter ticks across space, in turn, is a function of moose density but also winter tick survival. Research supports the density hypothesis (Samuel, 2007; Pekins, 2020). With more hosts, the potential for proliferation of parasites increases. As moose share similar needs, certain social cues and/or habitat quality may be driving their habitat selection decisions, which may be creating higher densities in particular areas on the landscape (i.e., hotspots) (Doligez et al., 2008; Blouin et al., in press). The abundance of questing winter ticks may also depend on the ground-level conditions between drop-off and questing (i.e., winter tick survival). Studies of winter ticks suggests that heavier tick loads in the fall may be influenced by the proportion of canopy cover (Samuel, 2007). Winter ticks have a higher chance of survival in more open forested habitats than canopied or closed habitats, due to sunlight and warmer temperatures (Drew and Samuel, 1986; Addison et al., 2016). Thus, moose that select habitats with both canopy structure and adequate forage structure (i.e., adult female moose with calves that survived; Figure 9), while unknowingly avoiding significant tick infestations, may be helping to identify habitats across the study area optimal for surviving ongoing tick epizootics. 

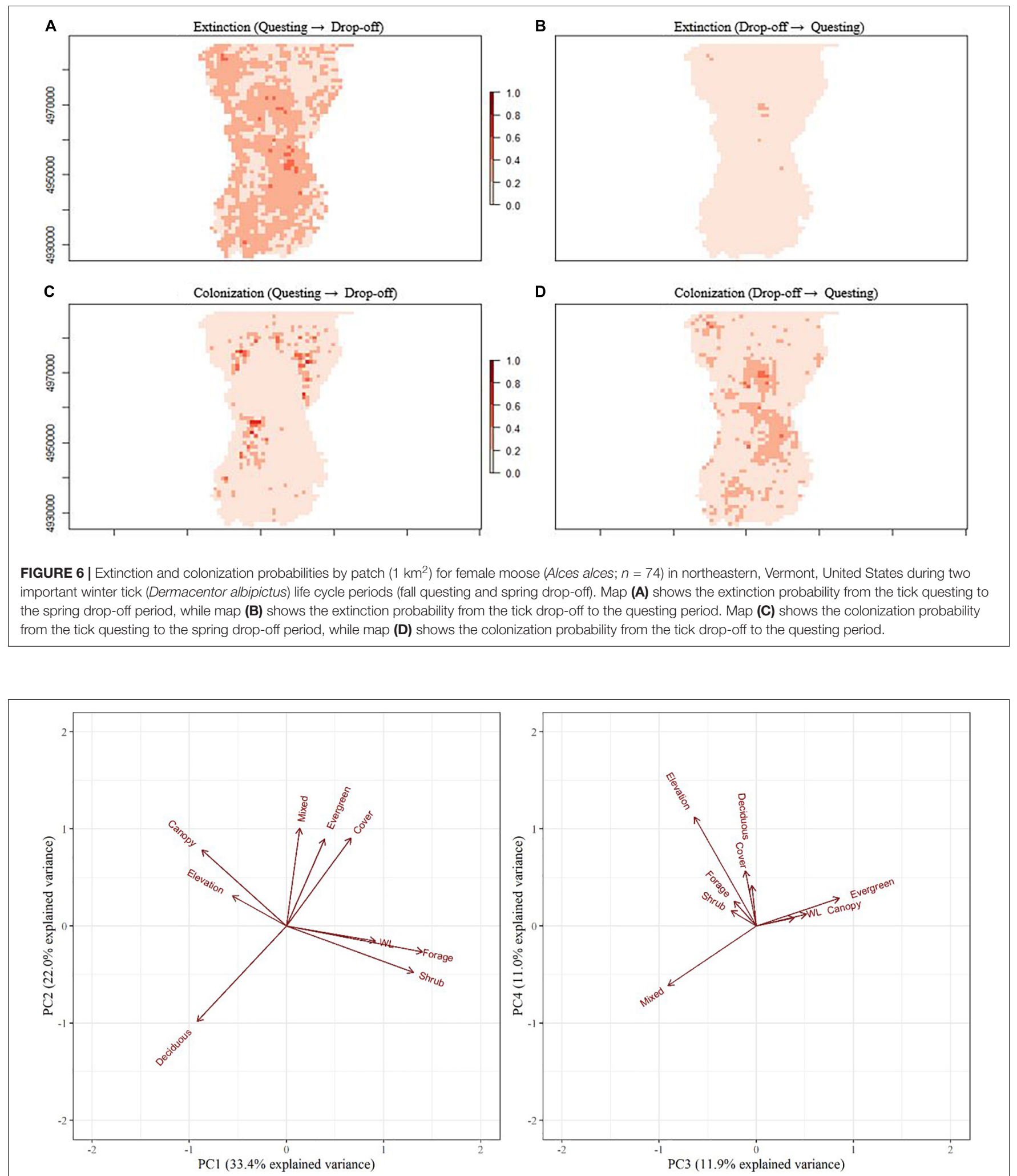

FIGURE 7 | Biplots of the top four principal components for objective 2 examining selection in relation to fitness. The biplot explains habitat variables selected by female moose (Alces alces; $n=10$ ) in northeastern Vermont, United States. The influence of each habitat variable on the components is expressed by the length and direction of the arrows (i.e., loadings). 
TABLE 6 | Resource selection function (RSF) coefficients for both a logistic and negative binomial model for female moose (Alces alces; $n=10$ ) with calves that survived $(n=5$, fate $=1)$ and those with calves that perished $(n=5$, fate $=0)$ in northeastern Vermont, United States.

\begin{tabular}{|c|c|c|c|c|c|c|}
\hline \multirow[b]{2}{*}{ Model } & \multirow[b]{2}{*}{ Fate } & \multirow[b]{2}{*}{ Parameter } & \multicolumn{4}{|c|}{ Estimates } \\
\hline & & & Min & Mean & Median & Max \\
\hline Logistic RSF & 0 & Intercept & -7.84 & -6.98 & -7.07 & -6.34 \\
\hline Logistic RSF & 0 & PC1 & -0.32 & 0.14 & 0.15 & 0.56 \\
\hline Logistic RSF & 0 & PC2 & -0.97 & -0.17 & 0.15 & 0.40 \\
\hline Logistic RSF & 0 & PC3 & -1.79 & -0.80 & -0.81 & 0.47 \\
\hline Logistic RSF & 0 & PC4 & -0.58 & 0.10 & 0.02 & 1.18 \\
\hline Logistic RSF & 1 & Intercept & -6.98 & -6.50 & -6.36 & -6.14 \\
\hline Logistic RSF & 1 & PC1 & -0.36 & 0.06 & 0.15 & 0.36 \\
\hline Logistic RSF & 1 & PC2 & -0.74 & -0.32 & -0.26 & -0.09 \\
\hline Logistic RSF & 1 & PC3 & -0.58 & 0.09 & 0.01 & 0.66 \\
\hline Logistic RSF & 1 & PC4 & -0.92 & -0.12 & -0.13 & 0.82 \\
\hline Negative Binomial RSF & 0 & Intercept & -7.74 & -7.05 & -7.22 & -6.14 \\
\hline Negative Binomial RSF & 0 & PC1 & -0.27 & 0.22 & 0.17 & 0.79 \\
\hline Negative Binomial RSF & 0 & PC2 & -1.36 & -0.29 & 0.07 & 0.34 \\
\hline Negative Binomial RSF & 0 & PC3 & -2.47 & -1.01 & -0.85 & 0.49 \\
\hline Negative Binomial RSF & 0 & PC4 & -0.83 & 0.09 & -0.02 & 1.34 \\
\hline Negative Binomial RSF & 1 & Intercept & -6.55 & -6.25 & -6.24 & -5.85 \\
\hline Negative Binomial RSF & 1 & PC1 & -0.27 & 0.18 & 0.33 & 0.56 \\
\hline Negative Binomial RSF & 1 & PC2 & -1.15 & -0.45 & -0.37 & 0.04 \\
\hline Negative Binomial RSF & 1 & PC3 & -0.45 & 0.22 & 0.42 & 0.79 \\
\hline Negative Binomial RSF & 1 & PC4 & -1.51 & -0.38 & -0.32 & 1.05 \\
\hline
\end{tabular}

Wildlife managers have considered a suite of actions that aim to reduce winter tick parasitism on moose. First, direct management strategies, such as hunter harvest, have been suggested to reduce the density of moose in certain areas where productivity and mortality are severely impacted by winter ticks (VFWD, 2020). Although moose have been in decline, further reduction of high local densities may be a proactive way to lessen the prolonged suffering and impacts from winter tick infestations (Mercer and McLaren, 2002; Ellingwood et al., 2020). Second, more indirect management strategies, such as the conservation, modification, or formation of certain habitat types may interrupt the tick-moose cycle. Forest management may change or manipulate the availability and quality of habitats, ultimately influencing these patterns of use and selection (Schrempp et al., 2019). Lastly, direct approaches to winter tick management are being explored to lessen the impact of ticks on moose fitness. The naturally occurring Metarhizium anisopliae fungus found in the soil has shown detrimental effects on winter tick survival in the laboratory setting (Sullivan et al., 2020).

Our analyses of first and second-order habitat selection, combined with Healy et al. (2018)'s third-order analysis, may inform all three of these potential management approaches. First, an understanding of where the probability of moose occupancy is highest may focus efforts of more direct management strategies, such as hunter harvest to reduce moose and tick densities. For instance, if the preferred method of management is to reduce local moose densities, reductions might be targeted on the areas or regions that have been encouraging the proliferation of ticks (Figures $\mathbf{6 A}, \mathbf{C}, \mathbf{9}$ ). In terms of habitat management strategies, our model coefficients and mapped results define "hotspots" for both moose and winter ticks as shrubby mixed/deciduous forest in higher elevations (Figures 6A,C, 9). Knowledge about these conditions may influence habitat management decisions, including the spatial distribution of such hotspots across the landscape. Further, timber management that encourages understory regeneration while maintaining some canopy structure (i.e., uneven-aged silviculture; habitats selected by adult female moose whose offspring survived), may be beneficial for moose fitness and detrimental to tick survival. In terms of direct winter tick management, information is lacking. Little is known about the ecology, abundance, and management of winter ticks in their natural setting. Managers may use the potential "hotspots" results to focus field research (e.g., Sullivan et al., 2020) that could ultimately help break the negative impacts of the tick-moose cycle.

Several caveats and questions remain. All 10 adult female moose-calf pairs were evaluated within the 2017 or 2018 questing period. During this time, Vermont experienced epizootic or near epizootic-level mortality (>50\%; 10-month old calves). Thus, our models of habitat selection investigated a snapshot in time of a host-parasite cycle; model results may differ in non-epizootic years. Moreover, it would be beneficial to know if an adult female's habitat selection patterns vary by year. We were unable to monitor adult female habitat selection and trace their offspring recruitment for more than a single year. Considering habitat selection of radio-collared individuals across time may lead to conclusions about whether decisions leading to decreased fitness by individuals is a recurring event or not. Further, we did not evaluate the composition of forest species that were selected by adult female moose during these time periods, the nutritional landscape (Schrempp et al., 2019), or the vegetation that is selected by winter ticks for questing in the fall. It is known that tree and shrub species vary in their nutritional value and availability for moose throughout the year (Timmermann and McNicol, 1988). Thus, future consideration of the availability and/or quality of forage during the fall questing or spring dropoff periods may be important for the management of both moose and winter ticks.

Additionally, our analyses focused on females and calves, yet males also act as wide-roaming vehicles of winter tick spread on the landscape. Throughout the growth season, male moose have much larger home ranges than females (Blouin et al., in press). More specifically, during the breeding season, mature male moose become territorial and may push younger males to more suboptimal habitats (Schwartz and Renecker, 2007). Additionally, male moose use scent urination to attract female moose and induce ovulation during the breeding period (Miquelle, 1991; Schwartz and Renecker, 2007). Research suggests that adult female moose may aggressively compete for access to bull urine (Miquelle, 1991), which may have important implications on habitat selection of female and their offspring during the questing period when moose are picking up ticks.

Finally, we did not examine winter tick success in terms of habitat selection of moose. One of the major influences on the severity of winter tick infestations is how favorable the conditions are for tick survival. This includes habitat structure and composition, but is also influenced by climatic 


\section{fate 官 Died 穴 Lived}
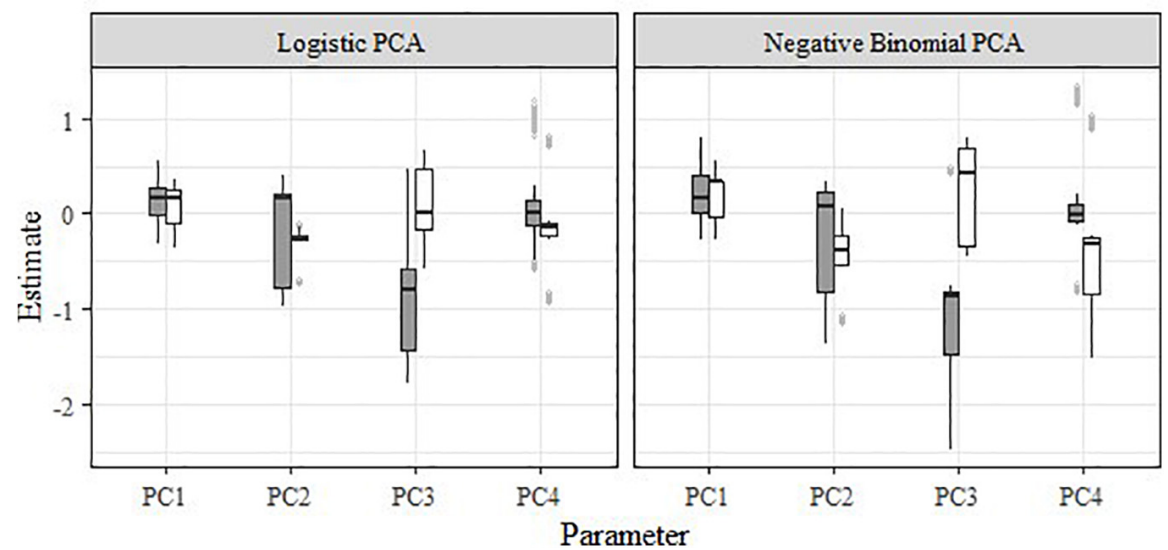

FIGURE 8 | Boxplot showing the impact of the top four principal components on habitat selection and fate (lived versus died) of adult female moose offspring (Alces alces; $n=10$ ) in northeastern Vermont, United States.
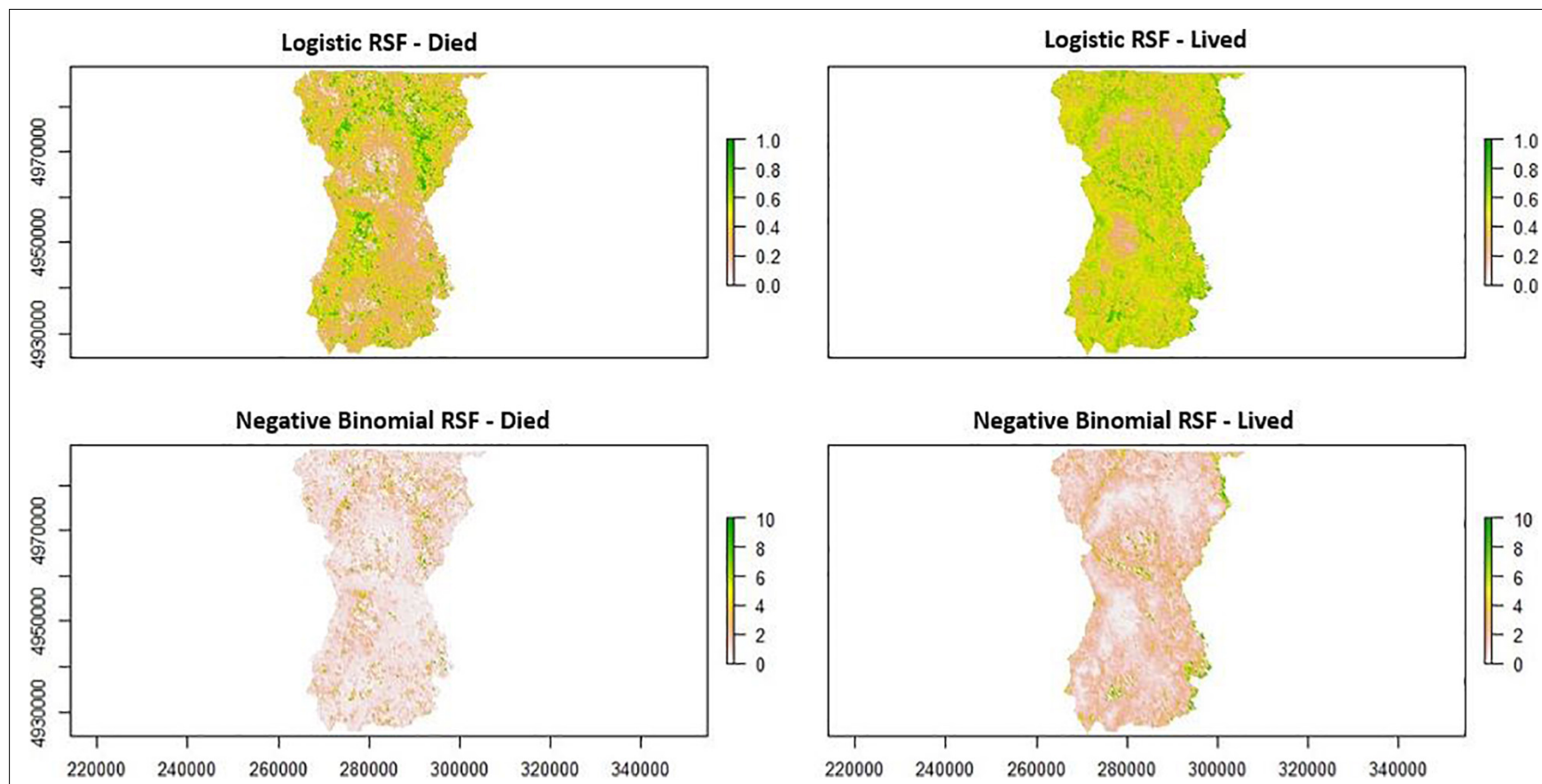

FIGURE 9 | A comparison of a logistic Resource Selection Function (RSF) and negative binomial Resource Selection Function (RSF) by female moose (Alces alces; $n=10$ ) during the fall winter tick (Dermacentor albipictus) questing period in northeastern Vermont, United States. Patches (200 m²) across the study area show areas female moose selected (green color) or did not select (white) during this time period for moose whose offspring lived versus those that died.

factors (i.e., onset of winter during the questing period or summer drought) (Samuel, 2007; Dunfey-Ball, 2017). Factors of a changing climate may ultimately be driving the winter tick-moose cycle by benefiting the survivability and success of ticks, thus consideration of weather patterns in relation to the acquisition of ticks and fate of moose may be beneficial.

Ultimately, the relationship between winter ticks and moose is complex. Perhaps equally complex is the appropriate and proactive management of moose populations in the face of changing climate patterns, encroaching human development, colliding public opinions, and ongoing consequences from increased parasitism. Structured decision making (SDM) approaches (e.g., Robinson et al., 2016; Franklin et al., 2020) can help managers weigh options and calculate trade-offs. Our aim was to provide science-based knowledge that may shed light on the habitats of importance to moose health that may be incorporated into SDM frameworks; in the end, this may lead to a better understanding of the multifaceted winter tick-moose cycle. 


\section{DATA AVAILABILITY STATEMENT}

The raw data supporting the conclusions of this article will be made available by the authors in the USGS repository, ScienceBase, after a 1 year embargo.

\section{ETHICS STATEMENT}

Animal capture and handling followed guidelines of the American Society of Mammalogists and all protocols were approved by the University of Vermont Institutional Animal Care and Use Committee (protocol \#17-035).

\section{AUTHOR CONTRIBUTIONS}

All authors contributed to the conception of ideas, designed the field methodology, and provided final edits for approval for publication. JD, ER, and JB collected the data. JB and TD designed analysis methodology and analyzed the data. $\mathrm{JH}$ assisted with RPresence analysis. JB and TD led the writing of the manuscript.

\section{FUNDING}

Funding was provided by the Vermont Fish and Wildlife Department in cooperation with the U.S. Fish and Wildlife

\section{REFERENCES}

Addison, E., McLaughlin, R., Addison, P., and Smith, J. (2016). Recruitment of winter ticks (Dermacentor albipictus) in contrasting forest habitats, Ontario, Canada. Alces 52, 29-40.

Addison, E. M., McLaughlin, R., and Broadfoot, J. (1998). Effects of winter tick (Dermacentor albipictus) on blood characteristics of captive moose (Alces alces). Alces 34, 189-199.

Addison, E., Fraser, D., and McLaughlin, R. (2019). Grooming and rubbings behavior by moose experimentally infested with winter ticks (Dermacentor albipictus). Alces 55, 23-35.

Ball, J. P., Nordengren, C., and Wallin, K. (2001). Partial migration by large ungulates: characteristics of seasonal moose Alces alces ranges in northern Sweden. Wildlife Biol. 7, 39-47. doi: 10.2981/wlb.2001. 007

Beyer, H. L., Haydon, D. T., Morales, J. M., Frair, J. L., Hebblewhite, M., Mitchell, M., et al. (2010). The interpretation of habitat preference metrics under useavailability designs. Philos. Trans. R. Soc. B Biol. Sci. 365, 2245-2254. doi: 10.1098/rstb.2010.0083

Blouin, J., DeBow, J., Rosenblatt, E., Alexander, C., Gieder, K., Murdoch, J., et al. (in press). Modeling moose habitat use by age, sex, and season in Vermont, USA using high-resolution lidar and National Land Cover data. Alces.

Boyce, M. S. (2006). Scale for resource selection functions. Divers. Distrib. 12, 269-276. doi: 10.1111/j.1366-9516.2006.00243.x

Burnham, K. P., and Anderson, D. R. (2002). A Practical Information-Theoretic Approach. Model Selection and Multimodel Inference, 2nd Edn. New York: Springer.

Cederlund, G., Sandegren, F., and Larsson, K. (1987). Summer movements of female moose and dispersal of their offspring. J. Wildlife Manag. 51, 342-352. doi: $10.2307 / 3801014$
Service Division of Wildlife and Sportfish Restoration Wildlife Restoration Program, the University of Vermont, U.S. Geological Survey Cooperative Agreement No. G19AC00241, Safari Club International Foundation, and Vermont Electric Power Company. Veterinarian consultation was funded and provided by the Northeast Wildlife Disease Cooperative. We are grateful for the support of the U.S. Fish and Wildlife Service National Wildlife Refuge System - Nulhegan Division (S. Agius), and land access from Weyerhaeuser Company, LandVest Inc., and many private landowners.

\section{ACKNOWLEDGMENTS}

We thank T. Smith, C. Lampart, L. Rossier, D. Hotchkiss, M. Luther, and E. Nichols for fieldwork assistance and S. MacFaden for lidar analysis. We appreciate the comments provided by Brittany Mosher, Stephanie McKay, and two reviewers, as they improved the clarity of the manuscript. We also thank D. Miller for perspectives on the use of multiseason occupancy methods to investigate habitat selection, and D. Dieffenbach for perspectives on resource selection functions. Any use of trade, firm, or product names is for descriptive purposes only and does not imply endorsement by the U.S. Government. The Vermont Cooperative Fish and Wildlife Research Unit is jointly supported by the U.S. Geological Survey, University of Vermont, Vermont Fish and Wildlife Department, and Wildlife Management Institute.

Cederlund, G. N., and Okarma, H. (1988). Home range and habitat use of adult female moose. J. Wildlife Manag. 52, 336-343. doi: 10.2307/380 1246

DeBow, J. (2020). Effects of Winter Ticks and Internal Parasites on Moose Survival and Fecundity in Vermont, USA. Master of Science thesis, University of Vermont, Burlington, VT, USA.

DeBow, J., Blouin, J., Rosenblatt, E., Gieder, K., Cottrell, W., Murdoch, J., et al. (in press). Effects of winter ticks and internal parasites on moose survival in vermont, USA. J. Wildlife Manag.

Doligez, B., Boulinier, T., and Fath, D. (2008). Habitat selection and habitat suitability preferences. Encyclopedia Ecol. 3, 1810-1830. doi: 10.1016/b978008045405-4.00015-x

Drew, M. L., and Samuel, W. (1986). Reproduction of the winter tick, Dermacentor albipictus, under field conditions in Alberta, Canada. Can. J. Zool. 64, 714-721. doi: $10.1139 /$ z86- 105

Dunfey-Ball, K. R. (2017). Moose Density, Habitat, and Winter Tick Epizootics in a Changing Climate. Master of Science thesis, University of New Hampshire, Durham.

Dussault, C., Ouellet, J. P., Courtois, R., Huot, J., Breton, L., and Jolicoeur, H. (2005). Linking moose habitat selection to limiting factors. Ecography 28, 619-628. doi: 10.1111/j.2005.0906-7590.04263.x

Ellingwood, D. D., Pekins, P. J., Jones, H., and Musante, A. R. (2020). Evaluating moose (Alces alces) population response to infestation level of winter ticks Dermacentor albipictus. Wildlife Biol. 2020:00619.

Forbes, G. J., and Theberge, J. B. (1993). Multiple landscape scales and winter distribution of moose (Alces alces) in a forest ecotone. Can. Field Nat. 107, 201-207.

Franklin, O., Krasovskiy, A., Kraxner, F., Platov, A., Shchepashchenko, D., Leduc, S., et al. (2020). Moose or spruce: a systems analysis model for managing conflicts between moose and forestry in Sweden. BioRxiv [Preprint]. doi: 10. $1101 / 2020.08 .11 .241372$ 
Fretwell, S. D. (1969). On territorial behavior and other factors influencing habitat distribution in birds. Acta Biotheor. 19, 45-52. doi: 10.1007/bf01601955

Healy, C., Pekins, P. J., Kantar, L., Congalton, R. G., and Atallah, S. (2018). Selective habitat use by moose during critical periods in the winter tick life cycle. Alces 54, 85-100. doi: 10.1016/j.mambio.2007.02.002

Hijmans, R., and Van Etten, J. (2012). Geographic Analysis and Modeling With Raster Data. R Package version 2.

Hines, J. E. (2006). PRESENCE 3.1 Software to Estimate Patch Occupancy and Related Parameters. Available online at: http://www.mbr-pwrc.usgs.gov/ software/presence.html (Accessed January 1, 2018).

Johnson, D. H. (1980). The comparison of usage and availability measurements for evaluating resource preference. Ecology 61, 65-71. doi: 10.2307/193 7156

Jones, H., Pekins, P., Kantar, L., Sidor, I., Ellingwood, D., Lichtenwalner, A., et al. (2019). Mortality assessment of moose (Alces alces) calves during successive years of winter tick (Dermacentor albipictus) epizootics in New Hampshire and Maine (USA). Can. J. Zool. 97, 22-30. doi: 10.1139/cjz-2018-0140

MacKenzie, D. I. (2006). Modeling the probability of resource use: the effect of, and dealing with, detecting a species imperfectly. J. Wildlife Manag. 70, 367-374. doi: 10.2193/0022-541x(2006)70[367:mtporu]2.0.co;2

MacKenzie, D. I., Nichols, J. D., Hines, J. E., Knutson, M. G., and Franklin, A. B. (2003). Estimating site occupancy, colonization, and local extinction when a species is detected imperfectly. Ecology 84, 2200-2207. doi: 10.1890/023090

MacKenzie, D. I., Nichols, J. D., Royle, J. A., Pollock, K. H., Bailey, L., and Hines, J. E. (2017). Occupancy Estimation and Modeling: Inferring Patterns and Dynamics of Species Occurrence. Cambridge, MA: Elsevier.

MacKenzie, D. I., Royle, J. A., Brown, J. A., Nichols, J. D., and Thompson, W. (2004). Occupancy Estimation and Modeling for Rare and Elusive Populations. Washington DC: Island Press.

Manly, B. F. J., McDonald, L. L., Thomas, D. L., McDonald, T. L., and Erickson, W. P. (2002). Resource Selection by Animals: Statistical Design and Analysis for Field Studies, 2nd Edn. Dordrecht, Netherlands: Kluwer.

Martin, J., McIntyre, C. L., Hines, J. E., Nichols, J. D., Schmutz, J. A., and MacCluskie, M. C. (2009). Dynamic multistate site occupancy models to evaluate hypotheses relevant to conservation of Golden Eagles in Denali National Park, Alaska. Biol. Conserv. 142, 2726-2731. doi: 10.1016/j.biocon. 2009.06.027

McPherson, M., Shostak, A. W., and Samuel, W. (2000). Climbing simulated vegetation to heights of ungulate hosts by larvae of Dermacentor albipictus (Acari: Ixodidae). J. Med. Entomol. 37, 114-120. doi: 10.1603/0022-2585-37. 1.114

Mercer, W., and McLaren, B. (2002). Evidence of carrying capacity effects in Newfoundland moose. Alces 38, 123-141.

Meyer, C. B., and Thuiller, W. (2006). Accuracy of resource selection functions across spatial scales. Divers. Distrib. 12, 288-297. doi: 10.1111/j.1366-9516. 2006.00241.x

Miquelle, D. G. (1991). Are moose mice? The function of scent urination in moose. Am. Nat. 138, 460-477. doi: 10.1086/285226

Musante, A. R., Pekins, P. J., and Scarpitti, D. L. (2007). Metabolic impacts of winter tick infestations on calf moose. Alces 43, 101-110.

NCDC (2019). Climate Data Online: Dataset Directory. Volume 2019. Asheville: National Climate Data Center.

Nikula, A., Heikkinen, S., and Helle, E. (2004). Habitat selection of adult moose Alces alces at two spatial scales in central Finland. Wildlife Biol. 10, 121-135. doi: 10.2981/wlb.2004.017

Pearman-Gillman, S. B., Katz, J. E., Mickey, R., Murdoch, J., and Donovan, T. (2020). Predicting wildlife distribution patterns in New England USA with expert elicitation techniques. Glob. Ecol. Conserv. 21:e00853. doi: 10.1016/j. gecco.2019.e00853
Pekins, P. J. (2020). Metabolic and population effects of winter tick infestations on moose: unique evolutionary circumstance? Front. Ecol. Evol. 8:176. doi: $10.3389 /$ fevo.2020.00176

R Core Team (2018). R: A Language and Environment for Statistical Computing. Vienna: R Development Core Team.

Robinson, K. F., Fuller, A. K., Hurst, J. E., Swift, B. L., Kirsch, A., Farquhar, J., et al. (2016). Structured decision making as a framework for large-scale wildlife harvest management decisions. Ecosphere 7:e01613.

Rosenblatt, E., DeBow, J., Blouin, J., Donovan, T., Murdoch, J., Creel, S., et al. (in press). Juvenile moose (Alces alces americana) stress and nutrition dynamics relation to landscape characteristics, climate-mediated factors, and survival. Conserv. Physiol.

Rosenzweig, M. L. (1981). A theory of habitat selection. Ecology 62, 327-335.

Samuel, B. (2004). White as a Ghost: Winter Ticks \& Moose. Volume 1. Canada: Nature Alberta.

Samuel, W. (2007). Factors affecting epizootics of winter ticks and mortality of moose. Alces 43, 39-48.

Schrempp, T. V., Rachlow, J. L., Johnson, T. R., Shipley, L. A., Long, R. A., Aycrigg, J. L., et al. (2019). Linking forest management to moose population trends: the role of the nutritional landscape. PLoS One 14:e0219128. doi: 10.1371/journal. pone. 0219128

Schwartz, C., and Renecker, L. (2007). Ecology and Management of the North American Moose. Washington, DC: Smithsonian Institution.

Schwartz, C. C., Hubbert, M. E., and Franzmann, A. W. (1988). Energy requirements of adult moose for winter maintenance. J. Wildlife Manag. 52, 26-33. doi: $10.2307 / 3801052$

Stearns, S. C. (1992). The Evolution of Life Histories. Cham: Springer.

Sullivan, C., Parker, B. L., Davari, A., Lee, M. R., Kim, J. S., and Skinner, M. (2020). Evaluation of spray applications of Metarhizium anisopliae, Metarhizium brunneum and Beauveria bassiana against larval winter ticks, Dermacentor albipictus. Exp. Appl. Acarol. 82, 559-570. doi: 10.1007/s10493-020-005 47-6

Terry, J. (2015). The Habitat of Winter Ticks (Dermacentor albipictus) in the Moose (Alces alces) Range of Northeast Minnesota. M.S. Thesis, University of Minnesota, Duluth.

Timmermann, H., and McNicol, J. (1988). Moose habitat needs. For. Chronicle 64, 238-245. doi: 10.5558/tfc64238-3

Thomas, D. L., and E. J. Taylor (2006). Study designs and tests for comparing resource use and availability II. J. Wildl. Manag. 70, 324-336. doi: 10.2193/0022541X(2006)70[324:SDATFC]2.0.CO;2

USGS (2016a). NLCD 2016 Land Cover Conterminous United States. Sioux Falls: U.S. Geological Survey.

USGS (2016b). USGS Lidar Point Cloud VT Connecticut-River 2016 N5495E569 LAS 2018: U.S. Geological Survey. Sioux Falls: U.S. Geological Survey.

VCGI (2002). Slopes generated from USGS NED based DEM24 data. Eric Pyle, VCGI. Waterbury: VCGI.

VFWD (2020). Big Game Management Plan: 2020-2030. Montpelier: Vermont Fish and Wildlife Department.

Conflict of Interest: The authors declare that the research was conducted in the absence of any commercial or financial relationships that could be construed as a potential conflict of interest.

Copyright (๔ 2021 Blouin, DeBow, Rosenblatt, Hines, Alexander, Gieder, Fortin, Murdoch and Donovan. This is an open-access article distributed under the terms of the Creative Commons Attribution License (CC BY). The use, distribution or reproduction in other forums is permitted, provided the original author(s) and the copyright owner(s) are credited and that the original publication in this journal is cited, in accordance with accepted academic practice. No use, distribution or reproduction is permitted which does not comply with these terms. 